\title{
EXPOSURE DURATION IN OVERHEATING ASSESSMENTS: A RETROFIT MODELLING STUDY
}

\author{
W. Victoria Lee ${ }^{a, b, c}$ and Koen Steemers ${ }^{c}$ \\ ${ }^{a}$ The Earth Institute, Columbia University, New York, NY, US \\ ${ }^{b}$ Department of Environmental Health Sciences, Mailman School of Public Health, Columbia \\ University, New York, NY, US \\ ${ }^{\mathrm{c}}$ The Martin Centre for Architectural and Urban Studies, Department of Architecture, University of \\ Cambridge, Cambridge, UK
}

\section{ABSTRACT}

A new indicator of overheating risk is introduced that more comprehensively represents heat stress and the way thermal environment is experienced. This indicator is compared with the industry standard overheating assessment approach (CIBSE TM52). This is demonstrated using an energy retrofit simulation case study of a typical London, UK terraced dwelling under different climate scenarios. Overheating was evaluated first according to TM52, then via an assessment of continuously overheated intervals (COIs) that account for the duration where adaptive limits are continuously exceeded. Results for the case study show that, first, extent of overheating can vary greatly based on climate uncertainties. Second, insulation retrofit only contributes to substantial overheating when the space lacks proper ventilation or protection from solar radiation.

Nevertheless, overheating cannot be avoided completely under future climate scenarios even with appropriate passive cooling. More importantly, the results show that overheated hours tend to occur consecutively. This implies that violations of TM52 criterion 1 (which currently applies only at the seasonal scale) can occur at the monthly/weekly resolutions. This 'buried' information can be revealed via the $\mathrm{COI}$ approach to more comprehensively capture how an overheating situation unfolds in a manner more relevant to heat stress and occupants' thermal experience.

\section{Keywords}

building performance; heat stress; houses; insulation; overheating; retrofit; simulation; thermal comfort

\section{INTRODUCTION}

While climate change has made heat stress an urgent issue in known warm regions, concerns for heat-related health impacts in the more temperate geographical regions are not to be overlooked. With the Intergovernmental Panel on Climate Change's (IPCC) prediction of a worldwide increase in the frequency and magnitude of warm daily temperature extremes (IPCC, 2012), the problem of overheating is not only escalating but also far-reaching. Studies have found that the relationship between heat and negative health effects can be clearly defined even for high-latitude places like Canada (Hajat \& Kosatky, 2010; Smoyer-Tomic, Kuhn, \& Hudson, 2003). In fact, it is the heat disasters that occurred in places with relative cool summers such as the 2003 European and 2010 Moscow heatwaves that have received most media attention in the past decade (WMO, 2011). While France and Italy were affected the most during the 2003 event, with each totalling around 
20,000 casualties (Robine et al., 2008), more than 2000 excess deaths were also reported in England and Wales (Johnson et al., 2005). ${ }^{1}$

Furthermore, a recent study suggested that in the absence of population adaptation, heatrelated deaths could increase by $257 \%$ by the 2050 s compared with the beginning of this century in the UK (i.e. from 1974 to 7040 deaths) - and affect all age groups, with the greatest risks expected for the most elderly (Hajat, Vardoulakis, Heaviside, \& Eggen, 2014). Specifically, London and the East Midlands were expected to be the most affected regions. In fact, when compared with the rest of England and Wales, historical data have already shown London inhabitants to be especially susceptible to the deleterious effects of heat (Hajat, Kovats, \& Lachowycz, 2007). Consequently, London provides a particularly interesting case for examining indoor thermal health. Ironically, because the primary thermal concern in places with a short cooling season like theUKis to keep warm, overheating due to refurbishment strategies aimed to reduce heating season energy consumption has emerged in recent years as a potential issue in addition to the warmer summers anticipated under climate change.

There are two reasons that made the unintended consequences of energy-efficient retrofits particularly relevant in the UK, where the world's first legally binding target has been set to reduce $\mathrm{CO} 2$ emissions by at least $80 \%$ (compared with the 1990 baseline) by mid-century (The National Archives, 2008). First, the domestic sector still accounts for around $17 \%$ of all carbon emissions in the UK in 2013, with most attributed to space heating (DECC, 2014). Second, the very slow building turnover rate in the domestic sector means that most of the dwellings today will remain standing in 2050. In fact, it is estimated that $70 \%$ of the 2050 housing stock in London, the East and the South East of England have already been built (Greater London Authority, 2008). Therefore, it is not surprising that there is a mounting urgency to retrofit the existing housing stock in order to reduce energy expenditures in the heating season.

However, some common retrofitting strategies - including insulation and draught-proofing to increase air-tightness - have understandably raised some concerns regarding the possibility of overheating in the summer (e.g. Mavrogianni et al., 2013; Shrubsole, Macmillan, Davies, \& May, 2014). The issue is complex and cannot be generalized. For instance, Mavrogianni et al. (2013) found that for typical Edwardian (pre-1918) solid-wall mid-terraced dwellings under a 2050 high emission (A1FI) climate scenario, externally applied wall insulation may actually reduce the total number of hours exceeding $26^{\circ} \mathrm{C}$ (which they deemed as overheated) by as much as $51 \%$ in the summer season. Internally applied insulation, on the other hand, was found to render inconclusive results. As buildings are dynamic systems that are further complicated by occupant interactions, it is only logical to anticipate that the indoor overheating situation would be affected by many different factors in addition to and in concert with any energy retrofits implemented. The more it is known about the manner with which overwhelmingly hot indoor environments unfold, the better informed building professionals can be of the trade-offs and potential health risks of a given retrofit strategy for a given building type.

The industry standard overheating assessment method as laid out in the Chartered Institution of Building Services Engineers (CIBSE) Technical Memorandum (TM) 52 (2013) has already addressed several facets of the overheating situation: occurrences, severity and absolute upper acceptability. The distinction of different overheating characteristics is already an improvement upon the myriad of thermal comfort and heat stress indices that have been developed over the past 150 years (Carlucci \& Pagliano, 2012; Epstein \& Moran, 2006; Parsons, 2003, p. 262). However, an overheating parameter that has yet to be accounted for by TM52 is exposure duration - the length of time one is continuously exposed to an overheated environment. Even the most recent review on overheating methodologies published by the Zero Carbon Hub (2015) noted that exposure duration

\footnotetext{
${ }^{1}$ The 2003 event was not a one-off occurrence for the UK. Analyses of the daily mortality data from 1993 to 2003 found heat-related mortality risks in all regions of England and Wales (Hajat et al., 2007). Increased risk on the hottest days was also found in a later study by Armstrong, Chalabi, Fenn, and Hajat (2011).
} 
is not covered by existing protocols despite acknowledging that prolonged exposure of even just moderately high temperature can have a significant negative effect on health and wellbeing.

The only assessment standard that takes duration into account is the heat stress index wet bulb globe temperature (WBGT) used in occupational and athletic settings (BSI, 1994). WBGT's calculation involves naturally ventilated wet-bulb temperature and black globe temperature, neither of which is commonly available as simulated output or logger-monitored parameter. A further shortcoming of WBGT is that it cannot be applied to assess conditions close to comfort (BSI, 1994). Although WBGT can be complemented via complete human physiological models such as the predicted heat strain (PHS) model in the most recent revision of ISO 7933, the PHS assessment procedure is complex, carrying many intermediate steps and using several different sub-indices, each of which has its own threshold to be checked against (BSI, 2005).

Although people may be more likely to experience thermal discomfort due to short, hot periods because they have not had the opportunity to adapt their behaviour or adjust their expectations (de Dear \& Brager, 2002), prolonged heat exposure is more likely to overwhelm the body physiologically even without the occupants' active awareness such as during sleep (Anderson, Carmichael, Murray, Dengel, \& Swainson, 2013; Gosling, McGregor, \& Lowe, 2009).

Many epidemiological studies over the years have found that the effects on health from heat for just one day is not the same as for successive days (e.g. Gosling et al., 2009; Montero, Miron, Criado, Linares, \& Diaz, 2010; Semenza et al., 1996; Tan et al., 2007). This is different than how cold affects health. Several studies explicitly examining the health effects of extended thermal stress have found that generally the duration of cold does not have an additional effect on mortality risk (Barnett, Hajat, Gasparrini, \& Rocklov, 2012; Lin, Ho, \& Wang, 2011; Rocklov, Ebi, \& Forsberg, 2011). On the contrary, most studies looking into the effect of prolonged heat exposure have found that mortality risk increases more from sustained periods of high temperature than from individual days (Anderson \& Bell, 2011; Barnett et al., 2012; Diaz et al., 2002; D'Ippoliti et al., 2010; Kinney, O'Neill, Bell, \& Schwartz, 2008; Lin et al., 2011; Rocklov et al., 2011, 2012; Williams et al., 2012). For example, in their study of Stockholm, Sweden, Rocklov et al. (2011) found that mortality risk increased proportionally with the length (in days) of heat exposure. Note that these studies are geographically diverse; coming from the US, Europe (including Sweden), as well as Canada, China, Taiwan and Australia. Unsurprisingly, long and intense heat exposure is found to be the most lethal (Hajat, Kovats, Atkinson, \& Haines, 2002). For example, the EuroHEAT project that compared the impact of heatwaves in nine European cities found that the death count was up to three times greater during extended periods of intense heat (D'Ippoliti et al., 2010). In fact, for the nine consecutive days during the 2003 European heatwave in France where the maximum temperature remained $11-12^{\circ} \mathrm{C}$ higher than the seasonal average, it was found that the daily excess mortality increased constantly (Fouillet et al., 2006). It is no surprise then that many heat warning systems incorporate some aspects of exposure duration into the conditions required for alert issuance. For example, among the different types of alerts issued by the US National Weather Service, a warning is released to the public when the forecasted heat index is equal or greater than $105^{\circ} \mathrm{F}\left(40.6^{\circ} \mathrm{C}\right)$ for more than three hours on two consecutive days (NOAA, 2011). The four-level heat-health watch system provided by Public Health England (PHE) also issues alerts based on threshold temperatures being reached or exceeded for 'at least two consecutive days' (Met Office, 2015).

More interestingly, several studies (Barnett et al., 2012; D'Ippoliti et al., 2010; Kalkstein \& Davis, 1989; Rocklov et al., 2011, 2012; Smoyer, 1998) have found that the mortality risk associated with duration is not necessarily shared by intensity, and that the intensity of heat may be of lesser importance than duration. In other words, how long the heat lasts contributes to separate mortality risk in addition to the risk related to the intensity of that heat. Admittedly, these epidemiological studies usually refer to the persistent or prolonged heat exposure in terms of consecutive days, not hours. This is because these population-level (i.e. ecological) health studies rely on data sources that are only available at a daily resolution (e.g. death certificates, hospitalization records, ambulance calls). From a physiological perspective, cumulative excess heat exposure is more likely to lead to 
dehydration and overload the cardiovascular system (Anderson \& Bell, 2011; Rocklov et al., 2011, 2012). For this reason, the international standard for estimating heat stress in workers - ISO 7243 (BSI, 1994) - stipulates a system of work-rest cycle, which operates at the hour resolution, to avoid heat strain in workers. The direction and concern of both health research and occupational safety indicate that the length of time one remains exposed to an overheated environment is consequential to thermal health and should be examined alongside overheating occurrence and severity. But this particular aspect of overheating cannot be gleaned from the existing approaches in building research.

This paper addresses two questions:

1. Can the existing approach to overheating risk assessment be augmented to include the additional parameter of exposure duration to render a more complete view of heat stress?

2. How may this additional means of examining overheating be applied to evaluate the extent cavity insulation, a common energy retrofit, contribute to summertime overheating when compared with the effects of climate change and occupants' behaviour (e.g. ventilation via operable windows)?

Using a simulated energy retrofit case study under different climate scenarios, this paper presents a twopart investigation to demonstrate how the analysis of overheating exposure duration can contribute additional insights that are useful to the evaluation of indoor overheating. The case study investigation in the second part serves as a vehicle to demonstrate how the method of accounting for exposure duration can be used. As such, the case study has a limited and specific scope looking at one room in one dwelling type with a small range of construction variations and occupant interactions with the building fabric:

- Part A is an explicit illustration of how crucial information regarding the way overheating unfolds can be left 'buried' by the existing assessment procedures. This analysis also shows that the 'missing' information can be 'reclaimed' by accounting for exposure duration through the evaluation of a new indicator: continuously overheated intervals (COIs) and suggests some possible ways of integrating the exposure duration aspect into the existing assessment approach.

- Part B investigates the extent of overheating, quantified using both the existing approach and COIs; and compares the outcome between two construction types and their insulated counterparts while considering the effects of the warming climate and building fabric interactions.

\section{METHODS}

Dynamic thermal simulations of a typical London mid-terraced dwelling were performed using Integrated Environmental Solutions Virtual Environment (IESVE) (Version 6.4). The main dynamic simulation engine of IES-VE is ApacheSim, which is based on first-principles mathematical modelling of the heat-transfer processes. It is linked to SunCast, which calculates the effects of solar shading; and MacroFlo, which calculates both wind-driven and buoyancy-induced bulk air movements based on a zonal airflow model to account for infiltration and natural ventilation (IES, 2011). The simulation setup included four construction types, two occupancy patterns, four window operation and two blind operation schedules under 21 sets of current and future climate scenarios. The operative temperatures for the summer season (May-September) of each scenario were then extracted and assessed for overheating.

\section{Existing assessment approach: TM52}

The industry standard of overheating assessment has been revised in recent years. Formerly, a common method as laid out in CIBSE Guide A (2007) and TM36 (2005) was to deem a space as overheated when more than $1 \%$ of the annual occupied hours have exceeded the benchmark $\left(\mathrm{T}_{\text {limit }}\right)$ 
of $28^{\circ} \mathrm{C}$ in operative temperature for living areas or $26^{\circ} \mathrm{C}$ for bedrooms. This assessment approach, based solely on the exceedance of a certain benchmark and a certain percentage of occupied hours, has been criticized for not considering the severity of the overheated condition (Nicol, Hacker, Spires, \& Davies, 2009; Spires, 2011). The CIBSE Overheating Task Force has since published a technical memorandum (TM52) (2013) specifically on evaluating overheating. The assessment guidelines laid out in TM52 is also referenced in the newly revised CIBSE Guide A (2015).

The TM52 approach consists of a 'suite' of three criteria (Table 1). A space is deemed overheated when two of the three criteria have been violated. Two sets of thresholds (noted as $\mathrm{T}_{\text {limit }}$ in Table 1) are used with these criteria: Categories I and III (equations (1) and (3) in Table 2). These are adaptive overheating benchmarks based on outdoor running-means as outlined in BS EN 15251 (BSI, 2007), which served as a basis for TM52. Category I - the 'stricter' of the two - is to be used for evaluating spaces occupied by 'very sensitive and fragile persons'; whereas Category III is to be used for existing buildings. ${ }^{2}$ The adaptive thresholds are to be used with naturally conditioned spaces in which the adaptive model posits that the comfort temperature varies daily with the outdoor temperatures, with the more recent experiences exerting more influence (CIBSE, 2013). Although the adaptive thresholds were derived based on field studies conducted in office buildings, they are also deemed applicable to residential situations where occupants are likely to be engaged in sedentary activities, as long as the space is unconditioned with operable windows and other means of adjusting the environments (BSI, 2007).

Table 1: Suite of three overheating criteria stipulated by CIBSE TM52 (2013)

\begin{tabular}{|c|c|}
\hline Criterion 1 & No more than $3 \%$ of total occupied hours during May-September exceeds $\mathrm{T}_{\text {limit }}{ }^{\mathrm{a}}$ \\
\hline Criterion 2 & Daily sum of degrees over $\overline{T_{\text {limit }} \text { a } a t ~ e a c h ~ o c c u p i e d ~ h o u r ~ d o e s ~ n o t ~ e x c e e d ~} 6$ degree-hours (K-hr) \\
\hline Criterion 3 & $T_{\text {op }}$ at any time when occupied does not exceed $\mathrm{T}_{\text {limit }}+4 \mathrm{~K}$ \\
\hline
\end{tabular}

a. an exceedance is considered as when the hourly operative temperature $T_{\text {op }}$ has exceeded $\mathrm{T}_{\text {limit }}$ by at least $1 \mathrm{~K}$ when rounded to the nearest whole degree

Table 2: Operative temperature benchmark thresholds ( $\left.T_{\text {limit }}\right)$ from BSEN 15251 (BSI, 2007)

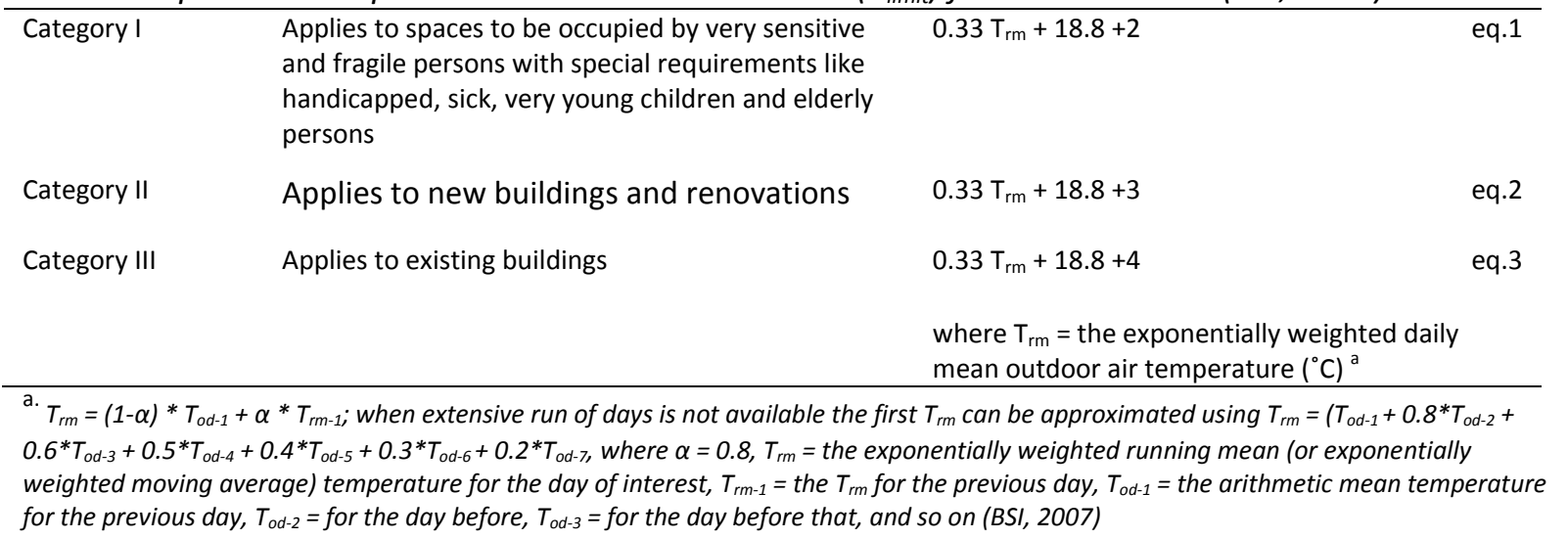

\footnotetext{
${ }^{2}$ CIBSE's US counterpart ASHRAE (American Society of Heating, Refrigerating, and Air-Conditioning Engineers) has a set of standard akin to BS EN 15251 - Standard 55 (2013). While Standard 55 does not provide explicit guidelines for assessing overheating, it supplies several different methods for determining the acceptability of specific thermal conditions. One of the methods was aimed to assess naturally conditioned spaces where occupants are engaged in mostly sedentary activities and are free to make other adjustments such as operating windows and changing their clothing levels. This method, similar to the one laid out in BS EN 15251, also utilizes the adaptive comfort concept to establish thresholds based on the prevailing mean outdoor air temperature. But unlike BS EN 15251 (or TM52), instead of three categories of thresholds Standard 55 has only two categories: $80 \%$ and $90 \%$ acceptability limits. The former is intended for general applications, whereas the latter is meant for situations where higher standard of comfort is desired. As Standard 55 does not specify any formal overheating assessment procedure, there are no explicit criteria whose violation will deem a space the 'overheated' status. But it also does not assess exposure duration.
} 
A further note on the Category I and III thresholds has to do with the 'adaptive' aspect of how these thresholds are calculated. Because the equations were developed based on regression analyses of field data collected under the 'current' climate (i.e. the recent past), and that the calculation depends on the outdoor temperature, it is unclear whether the equations can still be used as is when future climates are involved, such as in this case study demonstration. Given the increasing prevalence of mechanical cooling systems in buildings, people may become acclimatized to a narrower range of temperatures and develop high expectations of homogeneous environment with more frequent air-conditioning (Maller \& Strengers, 2011). For this reason, this study conservatively assumes that people's adaptability as characterized by the existing equations only applies to current climatic patterns. This means that $T_{\text {limit }}$ would continue to vary with $T_{r m}$ according to the equations in Table 2 as long as $T_{r m}$ remains less than $30^{\circ} \mathrm{C}$. Beyond $30^{\circ} \mathrm{C}$, which is the $T_{r m}$ upper limit for the equations to be valid (BSI, 2007), $T_{\text {limit }}$ would cease to increase with $T_{r m}$.

\section{Proposed assessment approach: continuously overheated intervals (COIs)}

In the second stage, the same data evaluated using the TM52 three criteria were examined in terms of overheating exposure duration. This means that the same hourly operative temperature $\left(T_{o p}\right)$ data were combed for COls. Specifically, this approach parses the total number of hours where $T_{\text {limit }}$ has been exceeded into several discrete intervals (Figure 1). As a result, instead of having a single number to represent the total aggregation of hours where Top exceeds $T_{\text {limit }}$ over the entire summer, the interval approach will render several COls, or stretches of time within each Top remains continuously above $\mathrm{T}_{\text {limit. }}$. It follows that each $\mathrm{COI}$ has a specific duration (time in hours) and a specific severity (the integral of the exceeded amount of degrees $(K)$ for the duration of the interval, represented by individual shaded regions in Figure 1). These individual interval durations and interval severities (in hours and K.hr, respectively) are termed as COI:duration and COI:severity. They provide two additional means to examine overheating risks.

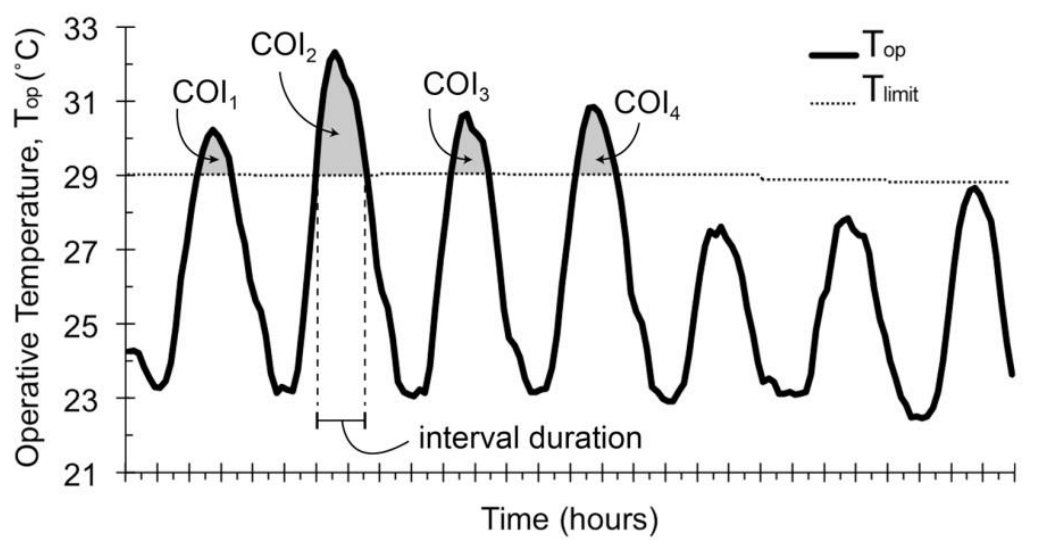

Figure 1: Sample of hourly operative temperature $\left(T_{o p}\right)$ data for seven days with a total of 31 hours where $T_{\text {op }}$ exceeded $T_{\text {limit }}$. This breaks down into four continuously overheated intervals (COls) each at six, ten, seven and eight hours long, respectively.

Neither COI:duration nor COI:severity encapsulate the cumulative effect of the entire COI. Therefore, a third means to examine overheating - COI:duration- severity - is necessary. COI:duration-severity convolves both the length of the $\mathrm{COI}$ (COI:duration) and the accreted degrees exceeding a given threshold (COI:severity) during the $\mathrm{COI}$ in such a way that the degree exceedance at a given sub-interval segment (e.g. the hourly degree exceedance) becomes increasingly more overwhelming the longer the $\mathrm{COI}$ lasts. This can be achieved by weighting the exceedance at a given sub-interval segment by the position of that sub-interval segment within a given $\mathrm{COI}$. The result is a more complete characterization of heat exposure duration of an individual COI. 
A question arises regarding how the 'weighting' should be done. ${ }^{3}$ In this exploration into using exposure duration in overheating assessments, three different speculative definitions of COI:duration-severity were proposed to represent some possible ways the cumulative effect of heat could develop with duration (Table 3). It is important to note that COI:duration-severity can be defined via other algorithms and this is an area of research that will require further development and consultation with health researchers. To make the results easier to compare, the computed values are natural logged (hence unit-less). For brevity and demonstration purposes, only definitions 1 and 3 as well as COI:duration are shown in the results presented in this paper. In total three means of accounting for overheating exposure duration were used in the demonstrative case study discussed below.

Table 3: Three example definitions of COI:duration-severity

\begin{tabular}{cc} 
Definitions & $\begin{array}{c}\text { Value (natural logged) of COI:duration-severity } \\
\text { for a hypothetical COI that has a constant } \\
\text { exceedance of 2K occurring at every hour for } 6 \\
\text { consecutive hours }\end{array}$ \\
\hline \hline & $\begin{array}{c}\text { COI:duration }=6 \\
\text { COI:severity }=2+2+2+2+2+2=12\end{array}$
\end{tabular}

Def. 1 Weighs the degree exceedance of any sub-interval (hourly) segment $\left(t_{i}\right)$ within a $\mathrm{COI}$ by the position of that hourly segment $i$, where $\mathrm{t}_{0}$ is when the COI begins; essentially the effect of the degree exceedance incurred in the second hour of the $\mathrm{COI}$ is considered to be twice as severe as if it were incurred in the first hour, and so on; i.e. the heat effect per degree exceeding a certain threshold to grow linearly with time

Def. 2 Considers the heat effect per degree exceeding a certain threshold to grow exponentially with time

Def. 3 Same as Def. 2 but the effect per degree exceeded only starts to compound after the first hour; this essentially suppresses the contribution of the first hour in any $\mathrm{COI}$ and allows the assumption that the brunt of the heat effect is shifted away from very brief (i.e. one hour) spikes

\author{
$1^{\text {st }} \mathrm{hr} \cdot * 2 \mathrm{~K}+2^{\text {nd }} \mathrm{hr} \cdot * 2 \mathrm{~K}+$

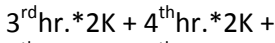 \\ $5^{\text {th hr. }} * 2 \mathrm{~K}+6^{\text {th }} \mathrm{hr} . * 2 \mathrm{~K}=42$ \\ $\operatorname{LN}(42)=3.7$
}

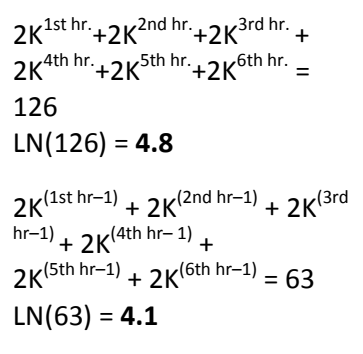

\section{External environment}

Weather files for London Islington (Central London) were used for the simulations. In addition to the 'current' climate, which is based on historical records for 1983- 2004 (Levermore \& Parkinson, 2006), three future climate time periods (2030, 2050 and 2080) of the medium (A1B) and high (A1FI) emission scenarios were also considered. The weather files for the projected climates were created by the PROMETHEUS project at the University of Exeter using the downscaled probabilistic climate data UKCP09 (Eames, Kershaw, \& Coley, 2011). For a given emission scenario and a given time period, almost the entire distribution of the probabilistic projection (which normally would require at least 3000 individual projection files to encapsulate) can be estimated with just five files of reference percentiles (10th, 33rd, 50th, 66th and 90th) (Kershaw, Eames, \& Coley 2011).

In total, weather files of five different climate scenarios were used: current, 2030(A1B), 2050(A1B), 2080 (A1B) and 2080(A1FI). Furthermore, each future climate scenario has separate files to represent five different reference probabilistic percentiles (10th, 33rd, 50th, 66th and 90th) of the

\footnotetext{
${ }^{3}$ Health studies have indicated that the effect heat exerts in successive exposures during a prolonged period is not the same as in the first instance. However, it has yet to be learned the mechanics of exactly how the cumulative effect of heat on health relates to its exposure duration such that the relationship can be described in a precise function or algorithm. Nevertheless, many studies examining the associations between mortality and heat have suggested that the physiological effects of heat exposure tend to follow an exponential pattern for both the exposure intensity and duration (Kinney et al., 2008; Marmor, 1978; Nakai, Itoh, \& Morimoto, 1999; Tan et al., 2010; Weisskopf et al., 2002).
} 
climate signal, rendering a total of 21 weather files for this case study. A 90th percentile 2050(A1B) climate file, for example, means that it is only $10 \%$ likely that the actual climate change (from the 1961- 1990 baseline) in the 2050s will be greater than the projected change presented by the data in the file under the A1B (medium emission) assumption. A detailed discussion on the representativeness of these weather files can be found in Eames et al. (2011), where the difference between test reference year (TRY) and design summer year (DSY) is also explained. In brief, the DSY format represents the near-extreme scenario or 90th percentile of the natural variability (regardless of the climate signal), whereas TRY format represents the statistically typical (50th percentile) scenario. This means that a 90th percentile DSY weather file represents a year of near-extreme weather in terms of natural variability as well as in terms of climate signal. DSY format is necessary when using existing overheating assessment methods. For comparison purposes, only DSY format weather files were used for the simulations carried out in this case study.

\section{Description of the case study dwelling}

Four thermally distinct constructions of a typical London mid-terraced dwelling (Figure 2) were considered: (1) unfilled cavity masonry (as-built); (2) timber frame (with brick exterior cladding); and $(3 / 4)$ their insulated counterparts. The dwelling has glazing on the south (total about $12 \mathrm{~m} 2$ ) and north (about $10 \mathrm{~m} 2$ ) facades and is assumed to be located in an area surrounded by other terraced dwellings at about equal height. These physical attributes were based on information available from the English Housing Survey (EHS) 2010 Housing Stock Data (DCLG, 2010). Specifically, the unfilled cavity masonry and timber-frame constructions were modelled after the mid-terraced dwelling samples from the age band 1967-75 in the London region. Descriptions of the four constructions and their U-values are provided in Table 4. As this paper aims primarily to demonstrate the COI approach in overheating assessments, only the results for bedroom 3 will be presented and analysed below. Bedroom 3 is of special overheating interest because it is located on the top floor under the roof and is south-facing.
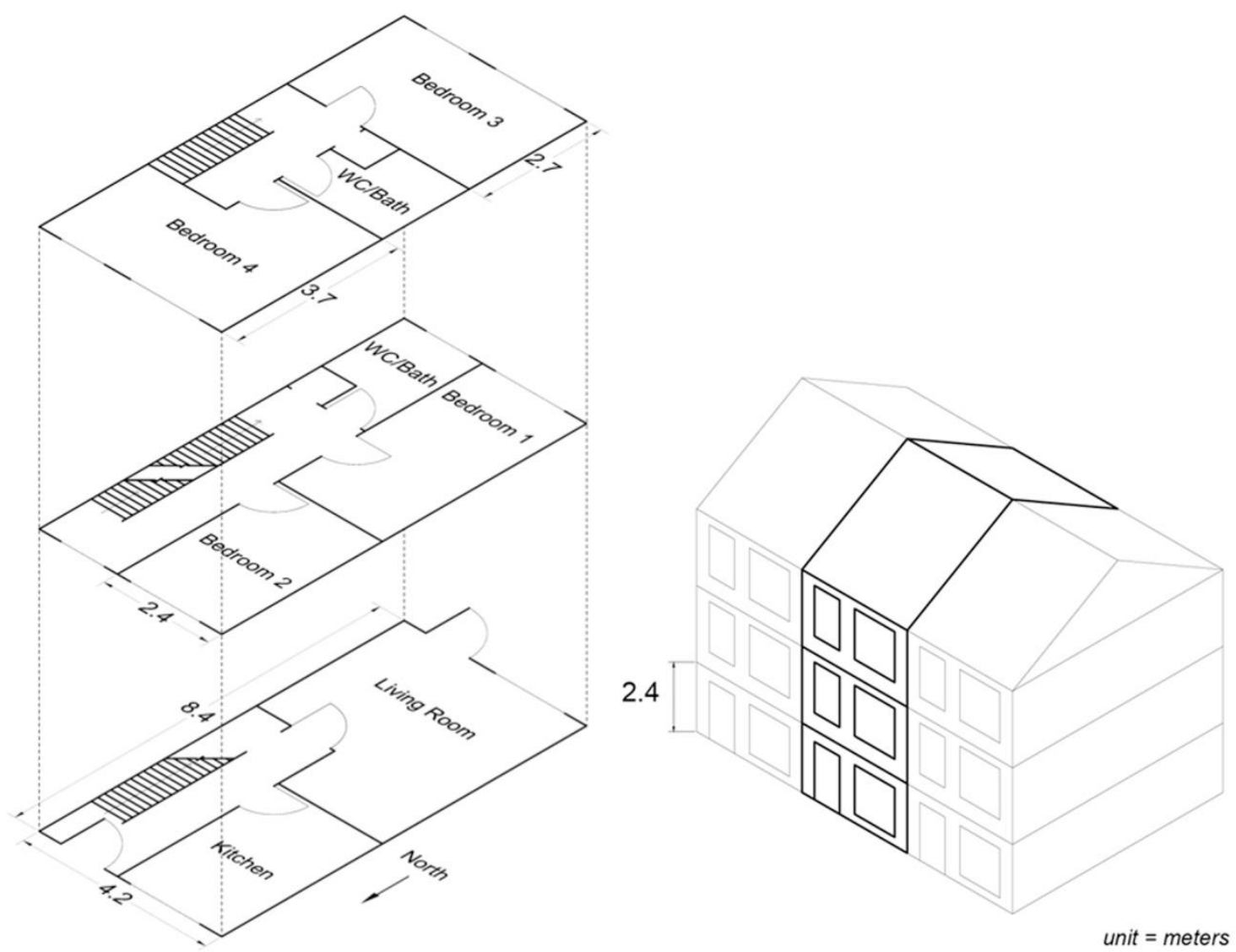

Figure 2: Plans of the case study dwelling (dimensions shown are internal and in metres). 
Table 4: Building construction descriptions and U-values for the case study dwelling

\begin{tabular}{|c|c|c|c|c|c|c|c|c|}
\hline \multicolumn{2}{|c|}{ Masonry Cavity - Uninsulated } & \multicolumn{2}{|c|}{ Masonry Cavity - Insulated } & \multicolumn{2}{|c|}{$\underline{\text { Timber Frame - Uninsulated }}$} & \multicolumn{2}{|c|}{$\underline{\text { Timber Frame - Insulated }}$} & \multirow[b]{2}{*}{$\frac{\text { Reference }}{\text { (BRE, 2010) }}$} \\
\hline $\begin{array}{c}\text { Construction } \\
\text { (thickness) }\end{array}$ & $\begin{array}{l}\text { U-Value } \\
\left(\mathrm{W} / \mathrm{m}^{2} \mathrm{k}\right)\end{array}$ & $\begin{array}{c}\text { Construction } \\
\text { (thickness) }\end{array}$ & $\begin{array}{l}\text { U-Value } \\
\left(\mathrm{W} / \mathrm{m}^{2} \mathrm{k}\right)\end{array}$ & $\begin{array}{c}\text { Construction } \\
\text { (thickness) }\end{array}$ & $\begin{array}{l}\text { U-Value } \\
\left(\mathrm{W} / \mathrm{m}^{2} \mathrm{k}\right)\end{array}$ & $\begin{array}{l}\text { Construction } \\
\text { (thickness) }\end{array}$ & $\begin{array}{l}\text { U-Value } \\
\left(\mathrm{W} / \mathrm{m}^{2} \mathrm{k}\right)\end{array}$ & \\
\hline \multicolumn{9}{|l|}{ External Wall } \\
\hline $\begin{array}{l}\text { Uninsulated cavity masonry } \\
\text { with dense plaster interior } \\
\text { finish }(0.25 \mathrm{~m})\end{array}$ & 1.6 & $\begin{array}{l}\text { Insulated/filled cavity } \\
\text { masonry with dense } \\
\text { plaster interior finish } \\
(0.25 \mathrm{~m})\end{array}$ & 0.5 & $\begin{array}{l}\text { Uninsulated timber } \\
\text { frame } w / \text { plasterboard } \\
\text { interior finish \& single- } \\
\text { leaf brick exterior } \\
\text { cladding }(0.27 \mathrm{~m})\end{array}$ & 0.8 & $\begin{array}{l}\text { Internally insulated timber } \\
\text { frame } w / \text { plasterboard } \\
\text { interior finish \& single-leaf } \\
\text { brick exterior cladding } \\
(0.31 \mathrm{~m})\end{array}$ & 0.4 & SAP Table S6 \\
\hline \multicolumn{9}{|l|}{ Party Wall } \\
\hline $\begin{array}{l}\text { Unfilled cavity wall with } \\
\text { dense block and dense } \\
\text { plaster interior finish } \\
(0.27 \mathrm{~m})\end{array}$ & $1.7^{\mathrm{a}}$ & $\begin{array}{l}\text { Insulated cavity wall } \\
\text { with dense block and } \\
\text { dense plaster interior } \\
\text { finish }(0.27 \mathrm{~m})\end{array}$ & 0.7 & $\begin{array}{l}\text { Uninsulated timber } \\
\text { frame with gypsum } \\
\text { plasterboard interior } \\
\text { finish }(0.26 \mathrm{~m})\end{array}$ & 0.6 & $\begin{array}{l}\text { Insulated timber frame } \\
\text { with gypsum plasterboard } \\
\text { interior finish }(0.26 \mathrm{~m})\end{array}$ & 0.3 & \\
\hline \multicolumn{9}{|l|}{ Internal Wall } \\
\hline $\begin{array}{l}\text { Dense block with dense } \\
\text { plaster interior finish } \\
(0.14 \mathrm{~m})\end{array}$ & 2.1 & Same as left & & $\begin{array}{l}\text { Uninsulated timber } \\
\text { frame with gypsum } \\
\text { plasterboard interior } \\
\text { finish }(0.14 \mathrm{~m})\end{array}$ & 0.9 & $\begin{array}{l}\text { Insulated timber frame } \\
\text { with gypsum plasterboard } \\
\text { interior finish }(0.14 \mathrm{~m})\end{array}$ & 0.5 & \\
\hline \multicolumn{9}{|l|}{ Doors and Windows } \\
\hline $\begin{array}{l}\text { Weatherstripped double- } \\
\text { glazed ( } 12 \mathrm{~mm} \text { gap air filled) } \\
\text { sash windows w/ PVC-U } \\
\text { frame ( } \sim 50 \% \text { openable area) }\end{array}$ & 2.8 & Same as left & & Same as left & & Same as left & & SAP Table 6e \\
\hline $\begin{array}{l}\text { Weatherstripped solid } \\
\text { wooden door to outside }\end{array}$ & 3.0 & Same as left & & Same as left & & Same as left & & SAP Table 6e \\
\hline Solid wooden internal doors & 1.4 & Same as left & & Same as left & & Same as left & & SAP Table 6e \\
\hline \multicolumn{9}{|l|}{ Floor/Ceiling } \\
\hline $\begin{array}{l}\text { Concrete slab, screeded } \\
\text { floor, no carpet }(0.25 \mathrm{~m})\end{array}$ & 2 & Same as left & & $\begin{array}{l}\text { Plasterboard ceiling, } \\
\text { carpeted chipboard } \\
\text { floor }(0.25 \mathrm{~m})\end{array}$ & 1.2 & $\begin{array}{l}\text { Plasterboard ceiling with } \\
\text { insulation \& carpeted } \\
\text { chipboard floor }(0.25 \mathrm{~m})\end{array}$ & 0.4 & \\
\hline \multicolumn{9}{|l|}{ Ground floor } \\
\hline $\begin{array}{l}\text { Slab on ground, screed over } \\
\text { insulation; no carpet }\end{array}$ & 0.4 & Same as left & & $\begin{array}{l}\text { Suspended timber, } \\
\text { insulation between } \\
\text { joist; carpeted }\end{array}$ & 0.5 & Same as left & & $\begin{array}{l}\text { comparable to } \\
\text { calculated by } \\
\text { SAP S5.4 }\end{array}$ \\
\hline \multicolumn{9}{|l|}{ Roof } \\
\hline $\begin{array}{l}\text { Pitched }\left(30^{\circ}\right) \text { tiled roof with } \\
100 \mathrm{~mm} \text { loft insulation }\end{array}$ & 0.4 & Same as left & & Same as left & & Same as left & & SAP Table S9 \\
\hline
\end{tabular}


The dwelling was assumed to be naturally ventilated during the non-heating season (AprilOctober). Ventilation was primarily achieved via window operations (discussed below); mechanical fans were not considered. Additional building operation assumptions and simulation settings can be found in Table 5. Wherever information is not available from the EHS data, values and assumptions were taken from or calculated according to SAP 2009 (BRE, 2010), CIBSE Guide A (2007), and ASHRAE Fundamentals (2009).

Table 5: Dwelling operation assumptions and simulation settings for the case study dwelling

\begin{tabular}{|c|c|}
\hline Natural ventilation & $\begin{array}{l}\text { - } \\
\text { - } \\
\text { Assutural ventilation } \\
\text { Housing Survey (EHS) data) (this is in addition to the infiltration via closed } \\
\text { windows, which is modelled dynamically by the simulation software IES-VE based } \\
\text { on the information from weather file input, including wind speed and direction) } \\
\text { - Assume the wind exposure type for all openings is sheltered as the location is in } \\
\text { central London residential area where surrounding buildings are about equal } \\
\text { height. } \\
\text { Assume all windows are either operable sash windows or top hung windows, } \\
\text { therefore openable areas for all window are set to half of total window area for } \\
\text { sash and } 100 \% \text { for top hung. }\end{array}$ \\
\hline Occupancy & $\begin{array}{l}\text { - Assumed dwellings are occupied by } 4 \text { people with a sensible heat output of } 70 \mathrm{~W} \\
\text { and latent heat output of } 45 \mathrm{~W} \text { while awake and engaging in sedentary and/or } \\
\text { very light work; } 60 \mathrm{~W} \text { and } 35 \mathrm{~W} \text {, respectively, while sleeping (in bedrooms) (CIBSE } \\
\text { Guide A, 2007) } \\
\text { Occupancy level is assumed to be } 1 \text { person in each of the } 4 \text { bedrooms and } 2 \\
\text { persons in the living room when it is occupied }\end{array}$ \\
\hline $\begin{array}{l}\text { Other internal heat } \\
\text { gains }\end{array}$ & $\begin{array}{l}\text { - Appliance gain follows occupancy schedule and is assumed to be } 200 \mathrm{~W} \text { for living } \\
\text { areas and 100W for bedrooms (during the first and last hours of occupancy) } \\
\text { (CIBSE Guide A, 2007; ASHRAE 2009) } \\
\text { - Lighting gain follows occupancy schedule and only applies when the outside } \\
\text { global horizontal solar flux (irradiance) is less than } 100 \mathrm{~W} / \mathrm{m}^{2} \text { (for bedrooms only } \\
\text { applies during the first and last hours of occupancy); the heat gain modelled } \\
\text { conforms to maintaining an illuminance of } 300 \text { lux in the living areas and } 100 \text { lux } \\
\text { in the bedrooms at lighting power density of approx. } 2 \mathrm{~W} / \mathrm{m}^{2} / 100 l u x \text { (CIBSE Guide } \\
\text { A, 2007; ASHRAE 2009) } \\
\text { No shading devices for windows except curtains/blinds; which are left } \\
\text { drawn/open during the day depending on the investigation (see main text) }\end{array}$ \\
\hline
\end{tabular}

Broadly, over half (54\% in 2011) of the English housing stock consists of terraced or semidetached dwellings, and most are of cavity-masonry constructions (64\% in 2011). In contrast, only around $3 \%$ of the dwellings are of timber-frame constructions. However, there is an increase in timber-frame dwellings in recent decades such that it accounts for around $8 \%$ of all homes built after 1980. The EHS report attributed this revival to the modern factory-built systems developed in the 1970s (DCLG, 2013). Therefore, in addition to examining the cavity-masonry mid-terraced dwelling type - one of the most common types of housing found in England - it is also of interest to consider the thermally distinct timber-frame construction, especially if there is a possibility that more newbuild dwellings would be of this type of construction. Furthermore, from a small survey sent out to the members of CIBSE, Gul and Menzies (2012) suggested that building professionals may have elevated concerns regarding overheating in timber-frame homes with high level of insulation.

Although timber-frame construction is commonly referred to as lightweight in the UK context (e.g. in Hacker, 2008; and Gul \& Menzies, 2012), the actual construction typically consists of a brick exterior cladding and therefore is not completely devoid of materials that would normally be considered as thermal mass. In an effort to distinguish more pronouncedly the different constructions examined in this case study, modifications to the descriptions provided by the EHS were made to render the cavity masonry construction more heavyweight, such as omitting the carpets and gypsum plasterboards, which are common for this dwelling type, in order to maximize the availability of thermal mass. 


\section{Occupant interactions with the building fabric}

Any attempt to account for real-life situations is inevitably intricate and necessarily incomplete as there are many factors to be considered. To deal with the complexity in a manageable manner, only two categories of occupant- building fabric interactions were considered: curtain/internal blinds and window operations. The former reduces solar radiation, whereas the latter aims to increase natural ventilation. The variety of potential overheating remedial or adaptive behaviours was kept deliberately minimal in order to focus on demonstrating the COI assessment approach.

Four window-operation scenarios were considered in this case study (Table 6); two of which are theoretical opposites ('worst' and 'ideal' scenarios, with respect to facilitating natural ventilation) and two account for more practical considerations ('realistic 1' and 'realistic 2'). The 'worst' scenario is one in which windows are never open and air exchanges are only achieved via infiltration (both structural and through closed windows). The 'ideal' scenario is where the windows are allowed to open whenever the indoor air temperature has exceeded the outdoor air temperature, and the indoor operative temperature has risen above the recommended summer comfort thresholds of $23^{\circ} \mathrm{C}$ for bedrooms and $25^{\circ} \mathrm{C}$ for living spaces, regardless of whether occupants are present to perform the operations. Temperatures of $23^{\circ} \mathrm{C}$ and $25^{\circ} \mathrm{C}$ are in fact the static limits stipulated by CIBSE Guide A (2007) for dwellings, which were superseded by the adaptive limits that fluctuate with daily outdoor running mean temperatures. Because the latter would be too complicated to implement with regard to occupant interactions (essentially requiring different thresholds for every day under assessment), the static thresholds were used instead.

Table 6: Window operation scenarios assumed in the case study dwelling

\begin{tabular}{|c|c|c|}
\hline Scenario & Full Description & The Gist \\
\hline Worst & $\begin{array}{l}\text { Assuming that windows are never open under any } \\
\text { circumstance }\end{array}$ & Windows never open \\
\hline Ideal & $\begin{array}{l}\text { Assuming that windows are open when the indoor } \\
\text { temperature exceeds the outdoor temperature and the } \\
\text { static comfort threshold of } 23^{\circ} \mathrm{C} \text { (this will be referred to in } \\
\text { shorthand as the "environmental criteria") regardless } \\
\text { whether the occupants are present to perform the operation }\end{array}$ & $\begin{array}{l}\text { Windows open whenever thermally beneficial to } \\
\text { do so }\end{array}$ \\
\hline Realistic 1 & $\begin{array}{l}\text { A more realistic scenario where the occupants maximise } \\
\text { natural ventilation opportunities and operate all windows in } \\
\text { the house according to the environmental criteria when } \\
\text { awake and at home but close all windows when away and } \\
\text { asleep due to security or noise concerns }\end{array}$ & $\begin{array}{l}\text { Windows open when thermally beneficial to do so } \\
\text { but only during 18:00 - 22:00 }\end{array}$ \\
\hline Realistic 2 & $\begin{array}{l}\text { Also a realistic scenario where the occupants maximise } \\
\text { natural ventilation opportunities and operate all windows in } \\
\text { the house according to the environmental criteria when } \\
\text { awake and at home; and close all windows when away but } \\
\text { leave all windows open when asleep (i.e. once open no } \\
\text { further engagement with the windows are assumed } \\
\text { throughout the night, as pointed out by Sharpe \& Shearer } \\
\text { (2013)) }\end{array}$ & $\begin{array}{l}\text { Windows open when thermally beneficial to do so } \\
\text { but only during 18:00-22:00; and left completely } \\
\text { open during } 22: 00-7: 00 \text { on weekdays and } 23: 00- \\
\text { 8:00 on weekends }\end{array}$ \\
\hline
\end{tabular}

Two 'realistic' scenarios were included, but even these considerations would not cover the level of complexity of real life. For example, in this case study it was assumed that if night-time ventilation were to take place while the occupants were asleep ('realistic 2'), all windows in the house would be left open. However, in reality the occupants may only leave a few windows open or half open, if at all. ${ }^{4}$ Practical concerns such as safety, noise, insects or pollutants may also deter opening the windows, even when thermally it would be beneficial to do so. 'Realistic 1 ' scenario takes these issues into account and only assumes window operations in the evenings from 18:00 to 22:00 hours. Nevertheless, people's actual window operation is unlikely to coincide exactly with

\footnotetext{
${ }^{4}$ Here it is assumed that if a window is open, it is open to its maximum equivalent orifice area.
} 
what would be deemed appropriate based on environmental criteria or be executed at the time the criteria are met; this is a limitation in modelling occupant behaviours. To prevent rapid compounding of occupant interaction settings, it was assumed that if the occupants were at home they would interact with all windows in the dwelling, a scenario not entirely the house and occupying different rooms at any one time. All internal doors were assumed to be closed. Although this may seem to impede potential cross-ventilation, preliminary testing (not presented here) indicated that it actually made little difference in the case of this particular test dwelling. Whilst occupant behaviours are complex, development of adaptive algorithms for occupant interactions with the building fabric and appliance operations are gaining grounds in building research (e.g. Rijal, Tuohy, Humphreys, Nicol, \& Samuel, 2012; Yun \& Steemers, 2008) and they could be used in future investigations.

To keep the occupant interactions with the dwelling more straightforward, only two blinds operation settings were considered: lowered or raised during the day, regardless of whether or not the windows were open. In practice, the use of blinds or curtains is likely to cause a reduction in the amount of ventilation that can be achieved through the open windows. In the simulated universe, however, both operations can be implemented without interfering with one another.

Logically, occupant interactions with the building fabric depends on them being physically present in the dwelling. ${ }^{5}$ While this does not affect the theoretical 'worst' and 'ideal' windowoperation scenarios (Table 6), how the occupancy schedule is determined does influence the two 'realistic' scenarios. The specification of occupancy period is also necessary for the TM52 assessment approach. For these reasons, the occupancy pattern was established as follows. The dwelling was assumed to have four occupants. The bedrooms were occupied only at night (22:00-07:00 hours on weekdays and 23:00-08:00 hours on weekends), whereas the living room was occupied mainly in the evenings on weekdays (07:00-08:00 and 18:00-22:00 hours) and for most of the day on the weekends (08:00-23:00 hours). Furthermore, each of the four bedrooms was set up to be occupied by one person each, whereas the living room was occupied by two when it was in use. For investigation purposes this arrangement approximates a plausible amount of internal heat gain within each room without overcrowding the dwelling on the whole. In any case, preliminary tests (not shown) indicated that the internal heat gain contributed by one or two occupants makes little difference with respect to the overall overheating situation.

To summarize the set-up of this simulation case study demonstration: overheating was assessed in two stages - first via an existing approach (TM52) followed by an interval approach that unpacks the overheating state via COls. The results for the uninsulated masonry cavity and the uninsulated timber-frame constructions of a typical London mid-terraced dwelling were compared against their energy refurbished (i.e. insulated) counterparts while considering the effects from the warming climate and building fabric interactions.

\section{RESULTS AND DISCUSSION}

\section{Part A: Comparing the existing assessment approach with the COI approach}

This first part of the case study is a close examination of TM52 criterion 1. For brevity and demonstration purposes only the results for bedroom 3 (a south-facing room under the roof; Figure 2) modelled in insulated cavity masonry construction, with the 'fragile' occupancy pattern (occupied at all times), no blind operation and window-opening schedule set to the 'ideal' case scenario (Table 6), is shown.

TM52 criterion 1 checks if the percentage of occupied hours that have exceeded the adaptive limits (of the category chosen) is over $3 \%$ of the total occupied hours for the entire nonheating season (May-September). This invites the question as to whether the $3 \%$ cap should also be applied to months, weeks or even days; and whether a different pattern might emerge when the

\footnotetext{
${ }^{5}$ Although smart systems and automated building controls are available today, these technologies are not widely implemented in the domestic setting.
} 
same data were inspected at these finer temporal resolutions. TM52 was developed based on European Standard BS EN 15251 (2007). According to the guidelines therein, the 3\% allowance should actually be observed for all resolutions. Based on the arithmetic, the number of hours that will amount to $3 \%$ for the entire non-heating season would not be the same as the number of hours that will constitute $3 \%$ for a single month or week. This means that there may be violations on a monthly, weekly or even daily basis that could be overlooked if only the non-heating season as a whole is considered.

Figure 3 shows the assessment results against Category I limits under the current and four future climate scenarios (at the 50th percentile) for bedroom 3. Rows a-c in Figure 3 represent the results for TM52 criteria 3, 2 and 1, respectively. The checkmarks and X-marks provide quick visual cues to whether the space has passed or violated each criterion. Since a space is only deemed overheated if two of the three criteria have been violated under TM52 guidelines, the tally of the check and Xmarks indicate that bedroom 3 is acceptable when evaluated at the seasonal resolution. Specifically, criterion 1 (row c) is not violated under any climate scenario. However, as soon as the data were examined at the monthly resolution, not only was there one month (July) under the 2080(A1FI) scenario that has exceeded the $3 \%$ limit (X-mark in row d), two other instances under the 2050(A1B) and 2080(A1B) climate scenarios also approached the $3 \%$ limit.

When the data were examined at the weekly resolution (row e), indeed one violation each emerged for 2050(A1B) and 2080(A1B); and three violations for the 2080(A1FI) scenario. Considering the fact that criterion 2 has already been violated for three of the four future climate scenarios examined here (2050(A1B), 2080(A1B) and 2080(A1FI) in row C), should the assessment have been done at the weekly resolution the newly 'revealed' criterion 1 violations would have caused bedroom 3 to be deemed as unacceptable from 2050 on; or at least to be unacceptable under the 2080(A1FI) climate scenario if evaluated at the monthly resolution (row d). Clearly, there are aspects of the overheated state that cannot be diagnosed by the existing assessment approach alone.

When exposure duration was assessed using the notion of COls, criterion 1 violations at finer resolution that were previously hidden in the seasonal aggregation were captured. The bottom three rows of Figure $3(\mathrm{f}-\mathrm{h})$ show the number of COls defined by the three exposure duration metrics introduced previously. COI:duration (f) accounts for the length of time (hours) that the COI lasts (i.e. where the temperature remains continuously above the threshold). On the other hand, COI:duration-severity definitions 1 and 3 ( $g$ and $h$ ) account for the degree exceedance weighted by the time lapse within the COI. Because the computed values were natural logged, the number of COIs defined using COI:duration-severity can only be categorized by unit-less ranges (as shown in Figure 3).

The choice of COI:duration, COI:duration-severity definitions 1 or 3, or any other way of defining COI:duration- severity is a decision that ultimately will need to be based on further health research to determine how many of what type of COls warrants concerns. Each metric also has its respective advantages and disadvantages. For instance, while COI:duration-severity is a more complete characterization of heat exposure duration because it convolves both the length and severity of a given $\mathrm{COI}$ to encapsulate the cumulative effect, the very convolution renders its values difficult to interpret and unintuitive, not to mention that there are many ways for such a convolution of which only two are speculated here (definitions 1 and 3). In contrast, while COI:duration by itself is not a complete characterization of a given $\mathrm{COI}$, its quantification in terms of consecutive hours (shorthanded as cons. hr in Figure 3 ) is accessible and can be easily intuited.

Regardless of which exposure duration metric is used, the COI assessment (either by COI:duration (row f), COI:duration-severity definition 1 (g), or COI:duration- severity definition $3(\mathrm{~h})$ ) simultaneously unpacks and summarizes the overheated state. Consequently, potential overheating issues for the space under evaluation can be quickly discerned. For instance, in row $\mathrm{f}$ (COI:duration) it can be plainly observed that under the 2080(A1FI) climate scenario there were several prolonged periods of indoor overheating, specifically eight COls lasting more than four hours, including one that was more than 12 consecutive hours long ( 14 hours to be precise). 


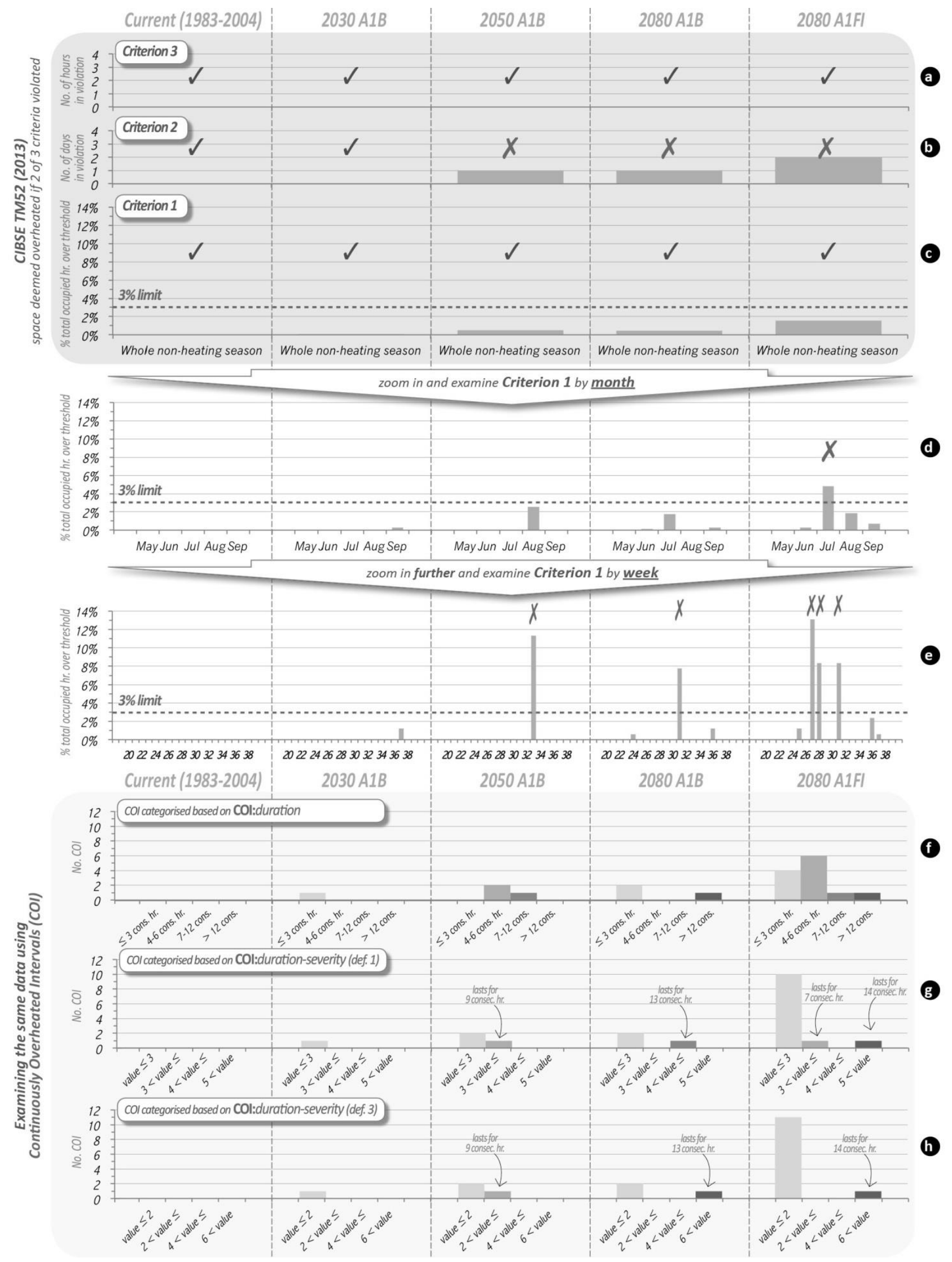

Figure 3: Assessment results against Category I limits under the current and four future climate scenarios (at the 50th percentile) for bedroom 3 modelled in insulated cavity masonry construction, with the 'fragile' occupancy pattern, no blind operation and window opening schedule set to the 'ideal' case scenario. 
Rows g (COI:duration-severity definition 1 ) and $\mathrm{h}$ (COI:duration-severity definition 3 ) further reveal that this 14-hour COI was not only long-lasting but also severe when defined in terms of COI:duration- severity. There was also one 13-hour-long COI under the 2080(A1B) scenario. In contrast, while no $\mathrm{COI}$ under the 2050 scenario exceeded 12 consecutive hours, there were more medium-length (4-6 and 7-12 consecutive hours) COls than under the 2080(A1B) scenario. These medium-length COls summed up to a higher total number of overheated hours (19 hours) under the 2050(A1B) scenario than under the 2080 (A1B) (16 hours). This subtle difference explains why, when aggregated (i.e. in rows $d$ and e, as well as in c albeit less obvious), that 'more' overheating occurred under a more recent future (2050 A1B) rather than in a more remote future (2080 A1B) climate.

These subtleties also suggest that in order to utilize more productively the information revealed by the $\mathrm{COI}$ assessment - for instance, if the $\mathrm{COI}$ approach is to be adapted and used with the TM52 guidelines as a fourth criterion - a benchmark limit of acceptability for each exposure duration metric would need to be set, much like the $3 \%$ limit for criterion 1 . While more research regarding the impact of heat duration on health is still needed to decide what these limits should be, in the meantime it may be possible to use provisional speculative benchmarks, such as 'no COls lasting longer than 6 consecutive hours', or 'no COIs having COI:duration- severity (definition 1) values larger than 5' or 'no COIs having COI:duration-severity (definition 3) values larger than 6' alongside existing assessment guidelines to build up a base of overheating investigations that account for exposure duration. These evidence-based cases may then help to incorporate healthoriented overheating criteria into assessment procedures for dwellings and perhaps other buildings as well.

While the provisional benchmarks such as those suggested above may seem arbitrary, the $3 \%$ limit for criterion 1 itself may also be considered as rather arbitrary. In fact, European Standard BS EN 15251 (the original source of the 3\% limit) allows either $3 \%$ or $5 \%$ to be chosen by individual country or authority as it sees fit. It was CIBSE that opted to take the conservative approach and adopted the $3 \%$ as the benchmark for criterion 1 (Fergus Nicol, personal communication, 25 April 2013). In any case, neither standard elaborates on the decision of the $3 \%$ limit or provides empirical basis for this selection. Accordingly, even in the absence of definitive recommendations from health sciences, it is conceivable that the evaluation of COls can be integrated into the existing overheating assessment procedure to account for heat exposure duration. Specifically, with speculative COI benchmarks such as those mentioned above, it is even possible to retain the pass-fail structure of the existing standards.

For instance, if two violations continue to be deemed as an indication of unacceptable overheating, and the $\mathrm{COI}$ assessment based on 'no COI:duration lasting longer than 6 consecutive hours' is adopted as the fourth criterion, then bedroom 3 would be deemed unacceptable from 2050 on (Table 7, option 1). But if the COI assessment based on 'no COI:duration-severity (definition 1) values exceeding 5 ' were used, then bedroom 3 would only be deemed unacceptable under the high emission 2080 scenario (A1FI) (Table 7, option 2). Again it should be emphasized that the COI-related benchmarks and threshold values used here are for illustrative purposes only. The important point is that exposure duration can be relatively easily accounted for even within the existing assessment framework.

Finally, note that confining the evaluation of the indoor thermal environment only to the occupied hours essentially deems that an unacceptable indoor thermal environment can be considered as acceptable as long as the occupants are not there to experience it. In reality, people's schedules differ and dwellings can be occupied according to a wide range of patterns. Therefore what is considered as 'occupied hours' in the assessment can be easily manipulated; so much so that it is known to be 'abused', as Nicol et al. (2009) have already pointed out. This is a problem that neither the existing nor the proposed $\mathrm{COI}$ assessment approaches can effectively address. Zero Carbon Hub's (2015) evidence review on overheating methodologies also highlighted this issue. 
Table 7: Tabulated checklist of criteria violations for Bedroom 3 based on Figure 3

\begin{tabular}{|c|c|c|c|c|c|c|}
\hline & & \multicolumn{5}{|c|}{ Climate Scenarios } \\
\hline & & $\begin{array}{l}\text { Current } \\
\text { (1983- } \\
\text { 2004) }\end{array}$ & $2030 \mathrm{~A} 1 \mathrm{~B}$ & $2050 \mathrm{~A} 1 \mathrm{~B}$ & $2080 \mathrm{~A} 1 \mathrm{~B}$ & $\begin{array}{l}2080 \\
\text { A1FI }\end{array}$ \\
\hline \multirow{3}{*}{ TM52 } & Criterion 1 & $\checkmark$ & $\checkmark$ & $\checkmark$ & $\checkmark$ & $\checkmark$ \\
\hline & Criterion 2 & $\checkmark$ & $\checkmark$ & $x$ & $x$ & $x$ \\
\hline & Criterion 3 & $\checkmark$ & $\checkmark$ & $\checkmark$ & $\checkmark$ & $\checkmark$ \\
\hline \multirow{3}{*}{$\begin{array}{l}\text { Sample } \\
\text { Criterion } 4\end{array}$} & $\begin{array}{l}\text { Option 1: } \\
\text { Based on COI:duration } \\
\text { "no COls lasting longer than } 6 \text { consecutive hours" }\end{array}$ & $\checkmark$ & $\checkmark$ & $x$ & $x$ & $x$ \\
\hline & $\begin{array}{l}\text { Option 2: } \\
\text { Based on COI:duration-severity (def. 1) } \\
\text { "no COIs having COI:duration-severity (def. 1) } \\
\text { values larger than 5" }\end{array}$ & $\checkmark$ & $\checkmark$ & $\checkmark$ & $\checkmark$ & $x$ \\
\hline & $\begin{array}{l}\text { Option 3: } \\
\text { Based on COI:duration-severity (def. 3) } \\
\text { "no COls having COI:duration-severity (def. 3) } \\
\text { values larger than 6" }\end{array}$ & $\checkmark$ & $\checkmark$ & $\checkmark$ & $x$ & $x$ \\
\hline
\end{tabular}

\section{Part B: Investigating the effect of insulation and fabric interactions}

This part of the case study compares the extent of overheating incurred in the four constructions while considering the concerted effects from the warming climate and building fabric interactions. The analyses take two forms: (1) assessments based on the TM52 suite of three criteria; and (2) assessments of COIs defined using three exposure duration metrics (COI:duration, COI:durationseverity definition 1 and COI:duration-severity definition 3 ).

\section{Components of the investigation}

Several different parameters were considered, including five climate scenarios, four constructions, four window- operation and two blind-operation scenarios. For brevity, only the results of three climate scenarios (current, 2030(A1B), 2080(A1B)) are presented. The discussion will primarily focus on bedroom 3, which is the south-facing bedroom under the roof (Figure 2), namely a space that on first principle is of the most overheating concern in the dwelling.

To better compare with TM52 criteria, the assessments targeted the occupied hours only this is the normative of the existing overheating assessment approaches. This means that for spaces designated as 'bedrooms' in the test dwelling (Figure 2) only the night-time (a span of nine hours from 22:00 to 07:00 hours on weekdays and from 23:00 to 08:00 hours on weekends) was considered. This time frame is how a bedroom in a mid-terraced dwelling would likely be evaluated given the general assumption is that people are not occupying the bedroom during the day. $\mathrm{A}$ summary of the components involved in the part B investigation is provided in Table 8.

The results presented below are organized as follows. Figure 5 contains the assessment outcomes against Category III thresholds for both the TM52 and COI assessments for bedroom 3 . Figure 6 contains the outcomes against Category I. Both figures are in the formation of a 'grid' of individual plots. Each column (eight in total, labelled sequentially from Figures 5 to 6 ) represents a particular combination of fabric interactions (e.g. 'worst' window-operation scenario and blinds 'not in use'). Each row (labelled a-f) represents the particular assessment method used. Specifically, rows $a-c$ display the results for the three TM52 criteria, whereas rows $d-f$ show the $C O I$ assessments each using a different duration metric. Individual plots of the grid in each figure have three regions, denoting the current (1983-2004), 2030(A1B) and 2080(A1B) climate scenarios. One exception is that for columns 1-4, only the results for 2030(A1B) and 2080(A1B) are shown because no violations were incurred under the current climate. Similarly, the results for the fabric interaction combinations involving 'realistic 2 ' and 'ideal' window-operation scenarios (Table 5) were omitted from the figures because those combinations incurred almost no TM52 criteria violations and no 
COls. The results for the future climate scenarios are presented in a box-whisker format, with the boxes and whiskers indicating the different probabilistic percentile projections of the future climate scenario (see the legend in Figure 4).

Table 8: Summary of components for the Part B investigation

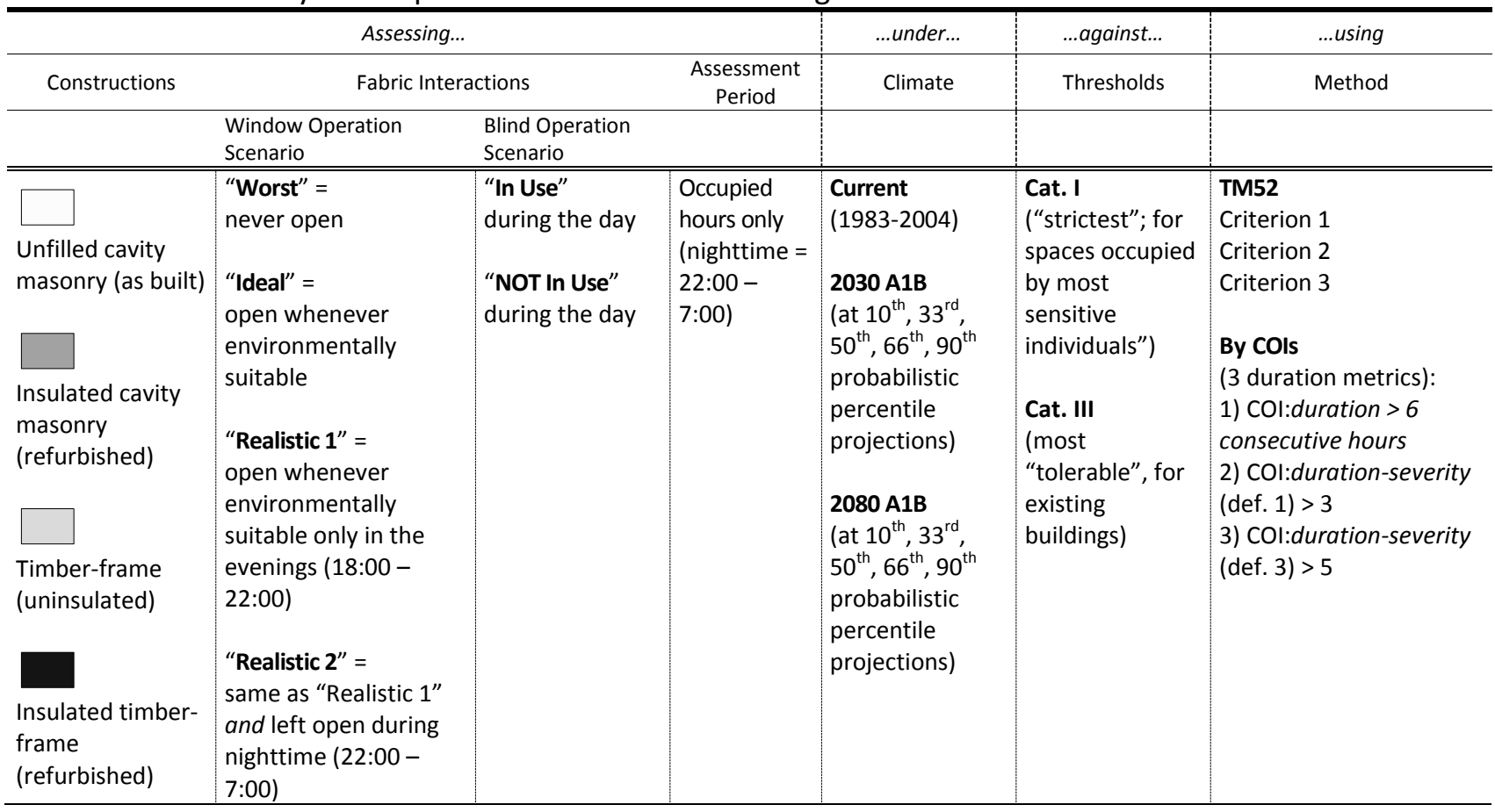

\section{Overall observations}

Several global observations of the assessments as a whole can be made before comparing the constructions and fabric interactions. First, for almost all the plots in Figures 5 and 6 (regardless of construction type, fabric interaction, threshold or assessment period), there are considerable variations in the results for the future climate scenarios (2030(A1B) and 2080(A1B)) as shown by the lengths of the box-whisker plots. This indicates that even within the same future climate scenario (e.g. 2030(A1B)), there is a relatively high degree of uncertainty regarding the overheating assessment results due to the uncertainty of the future climate projections and this occurred in both the TM52 assessments and the COI evaluations. The common practice for studies focusing on comparing building types, characteristics or interventions is to select one of the five available percentiles, such as the 50th percentile to represent a median climate signal projection (albeit on the near-extreme end of natural variability due to the DSY format) (e.g. Mavrogianni, Wilkinson, Davies, Biddulph, \& Oikonomou, 2012; Oikonomou et al., 2012); or the 90th percentile to represent a 'worst'-case scenario (the near-extreme end of natural variability and the near-extreme end of climate signal) (e.g. Gupta \& Gregg, 2012).

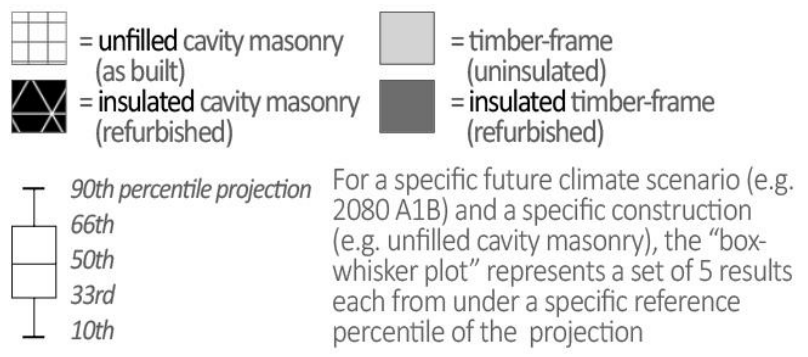

Figure 4: Legend for the plots shown in Figures 5 and 6. 


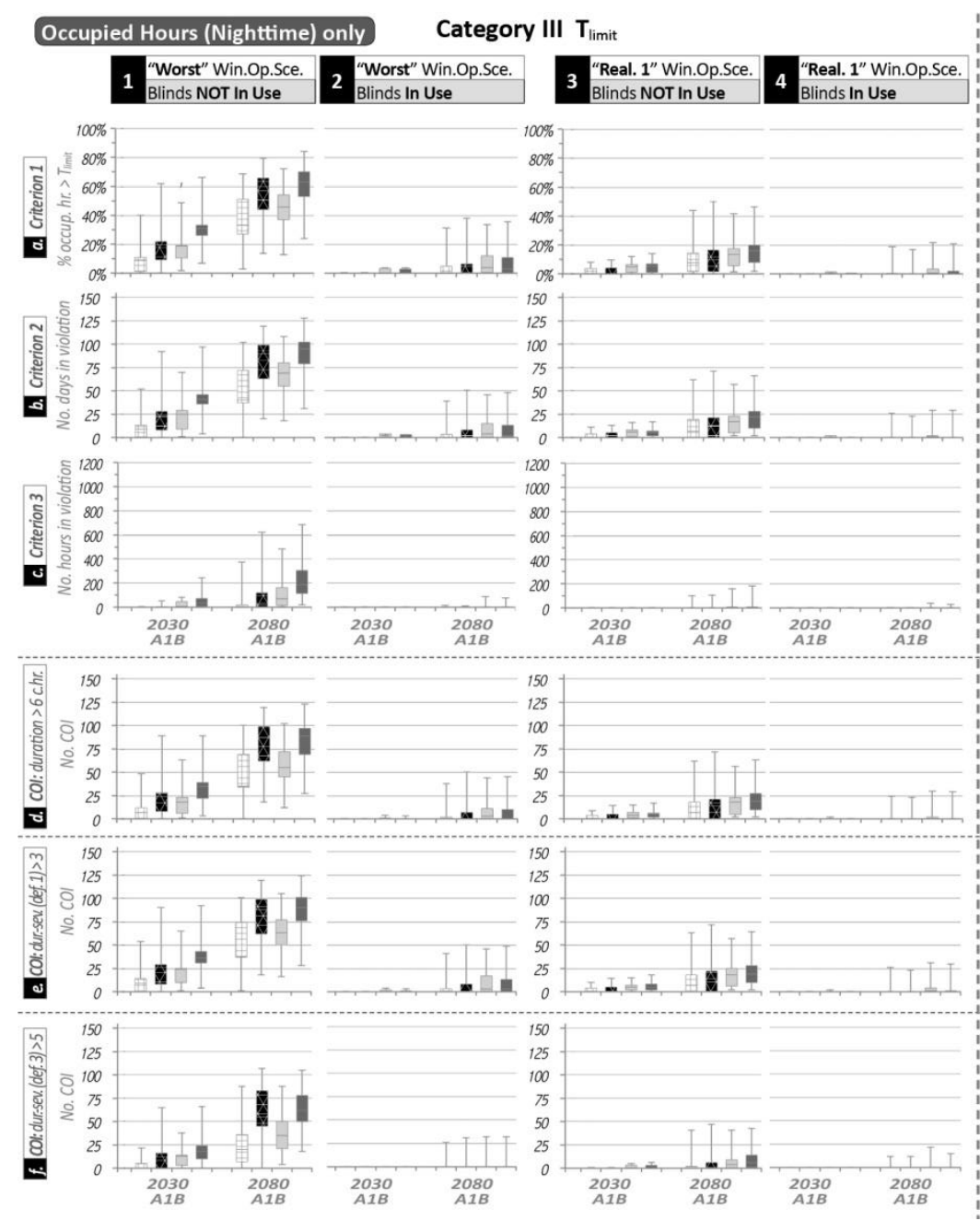

Figure 5: Bedroom 3 occupied hours only (night-time):

assessment results based on TM52 criteria (rows $a-c$ ) and COls (rows $d-f$ ) against Category III limits.

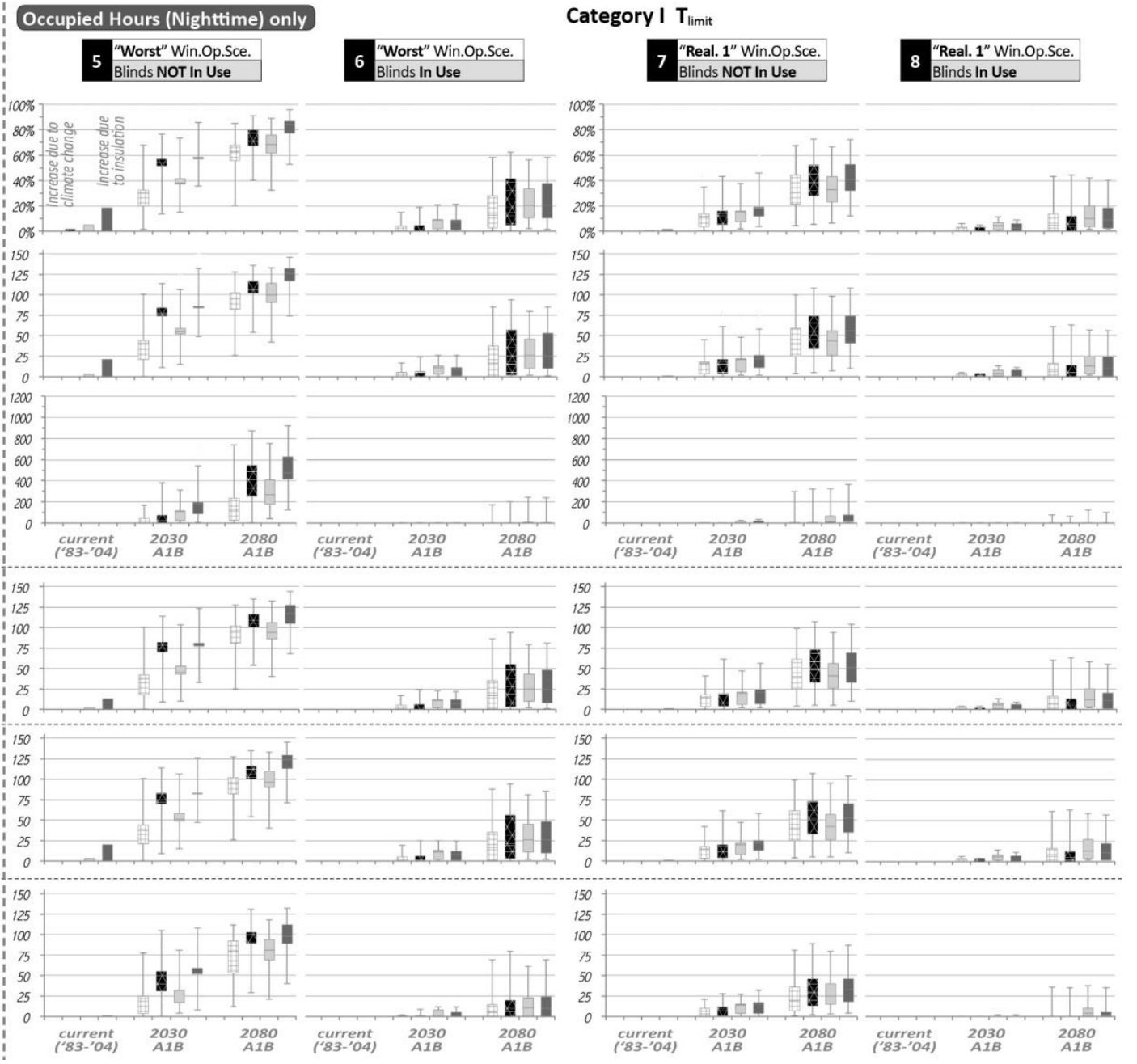

Figure 6: Bedroom 3 occupied hours only (night-time):

assessment results based on TM52 criteria (rows $a-c$ ) and

COls (rows $d-f$ ) against Category I limits 
These are all very sensible choices but the fact remains that the outcome of what is considered 'overheated' is very heavily influenced by the probabilistic percentile of the climate projection, even for the exact same location and the exact same climate scenario. This can be especially problematic if overheating continues to be assessed on a binary basis, because the outcome can be flipped simply by selecting a different percentile projection.

Meaningful comparisons can still be made especially if the analysis is based on the 'box' portion of the box- whisker plots, which is meant to represent the 33rd to 66th percentiles on the probability projection spectrum (Figure 4). This could be considered as a reasonable compromise between accounting for some degree of climate uncertainty and allowing for distinct enough comparisons among the different constructions and fabric interactions relative to one another.

The second overall observation is also related to the probabilistic percentiles of the future climate projections. Within a specific future climate scenario (e.g. 2030 (A1B)), one would reasonably expect that the 90th percentile projection file would represent the warmest outdoor environment among the five reference percentiles and therefore incur the most serious TM52 criteria violations. This assumption means that the individual box- whisker plots reflect the order as shown in the legend in Figure 4 where the top whisker represents the value for the 90th percentile projection, the top of the box represents the value for the 66th percentile, and so on.

However, this was not necessarily always the case. Indeed, there were numerous deviations from the expected 'order' (marked with '!' in Figure 5). Sometimes it was in fact the 10th percentile (not the 90th) that produced the highest number of TM52 criteria violations. ${ }^{6}$ The fact that these deviations from the expected outcomes exist suggests that the usual assumptions - such that a 50th percentile projection could be used to represent a median outdoor environment and a 90th percentile a 'worst'-case scenario - could potentially be misleading, especially given the fact that the assessment results can vary so widely based on which percentile projection of the climate scenario is used. In other words, while a 90th percentile projection would be hotter than a lower percentile projection when taking the entire year into account, there may be periods of overheating that is either more severe or more frequent in the lower percentile projections when considering all climatological variables and their interactions in concert with the building characteristics.

\section{Construction and fabric interaction comparisons under current climate}

When assessing only the occupied hours (night-time) for bedroom 3 under the current climate, the cavity masonry constructions, both as-built (unfilled) and refurbished (insulated), did not pose any overheating concerns when assessed against either Category III (not shown) or Category I (columns 5-8 in Figure 6) thresholds, even under the most inauspicious conditions ('worst' window-operating scenario and no solar protection, column 5). On the other hand, the refurbished (insulated) timber-frame construction violated TM52 criteria 1 and 2 and incurred several COls lasting more than half of the night (more than six consecutive hours) when assessed against the sensitive Category I threshold. Specifically, when using COI:duration as the metric (column 5 row $d$ in Figure 6 ) there were 13 COls (with the longest ones lasting the entire night - nine consecutive hours); and 20 COls with logged COI:duration-severity (definition 1) value greater than three (column 5 row e in Figure 6). Nevertheless, this extent of overheating (with respect to both TM52 criteria and COIs) can be eliminated simply by either lowering the blinds during the day (column 6 in Figure 6) or by allowing the windows to open for only four hours in the evening ('realistic 1' window-operating scenario) (column 7 in Figure 6).

\footnotetext{
${ }^{6}$ While these occurrences are not intuitively expected, they are also not entirely surprising because the five reference probabilistic percentiles are based solely on mean monthly air temperature (Eames et al., 2011). This means that even when the air temperature may be at the near extreme end of the probabilistic spectrum (e.g. 90th percentile), the other climatological parameters that can also influence a building's performance may not necessarily be of the same percentile on the spectrum (i.e. not near the extreme end).
} 
Construction and fabric interaction comparisons under future climate

A more problematic picture emerged when assessing under the future climates, where more pronounced trends can be discerned. First, when windows were never allowed to open ('worst' scenario) and the blinds were not in use, all constructions would be deemed as overheated by TM52 criteria for the entire occupied period at night even when assessed against the least sensitive threshold (Category III) (column 1 in Figure 5). More importantly, it became evident across both Category I and III thresholds and both the TM52 and COI assessments that insulated timber-frame construction is the most problematic, incurring the most egregious TM52 violations and the most number of COIs longer than six consecutive hours.

Furthermore, more overheating was caused by the refurbishment (insulation addition) than by the construction's available thermal mass. This is illustrated by the fact that more overheating was observed in the insulated masonry construction than in the uninsulated timber-frame construction. This suggests that - at least for the four constructions of the particular mid-terraced dwelling type examined here - when there is no provision for natural ventilation or solar protection (columns 1 and 5), the unintended overheating that could be incurred by insulation under future climates outweigh any potential overheating remedial effect that the presence of thermal mass in the masonry construction may offer, especially under the 2080 climate scenario. What is observed here aligns with the general recommendation such that thermal mass application should be coupled with appropriate ventilation to avoid overheating (CIBSE, 2007).

While it is clear that within each construction weight (cavity masonry or timber-frame) the insulated variants always perform worse when no natural ventilation or solar protection was provided, the increase in overheating due to insulation were generally less than the increases due to climate change for both assessments using TM52 criteria and COIs.

Figure 7 compares the increase in overheating due to insulation against the increase due to future climate scenarios (50th percentile). The comparison was carried out twice: once using the current climate as the basis to compare with (Figure 7, light grey shaded background), and once using the 2030 climate (unshaded background). For the most part the increase due to insulation (white bars) were less than the increase due to climate change (the hatched bars), especially from the current climate to the 2030 climate for the cavity masonry construction. In almost all instances the difference between the increase due to insulation (within the same climate scenario) and the increase due to climate change decreased when moving from comparing the current climate with the 2030 climate to comparing the 2030 climate with the 2080 climate (e.g. the brackets drawn in row a of Figure 7). This suggests that while in the near future the overheating effect attributable to insulation may be less than the overheating effect caused simply by the warming climate, the undesirability of insulation may become more problematic with the ever-more-demanding outdoor environment. Nevertheless, again it should be noted that Figure 7 is only a demonstration that presents a scenario when no natural ventilation or solar protection was provided. The concerted overheating contribution of energy retrofits such as insulation under a warming climate is an issue that will need to be explored further in future work.

The difference between the insulated and uninsulated or between the cavity masonry and timber-frame constructions became trivial when fabric interactions were introduced. Both the blinds and the four-hour evening ('realistic 1' scenario) window operations (alone or combined) were very effective in reducing the number and extent of the TM52 violations, as well as the number of COIs. This echoed what was already observed under the current climate. Nevertheless, overheating could not be completely eliminated especially under the 2080(A1B) climate scenario even when assessed against the less strict Category III threshold (column 2-4 in Figure 5). Although solar protection through the use of blinds proved to be very effective, to reduce overheating in bedroom 3 such that it is no longer deemed as overheated per TM52 criteria or is rid of any COI's longer than six consecutive hours would require that the windows be left open all night ('realistic 2' windowoperation scenario) or be allowed to open whenever it is environmentally suitable to do so ('ideal' 
scenario) (hence these graphs are not shown in Figures 5 and 6). In other words, where night-time occupied hours are concerned, ventilation is more important than solar protection.
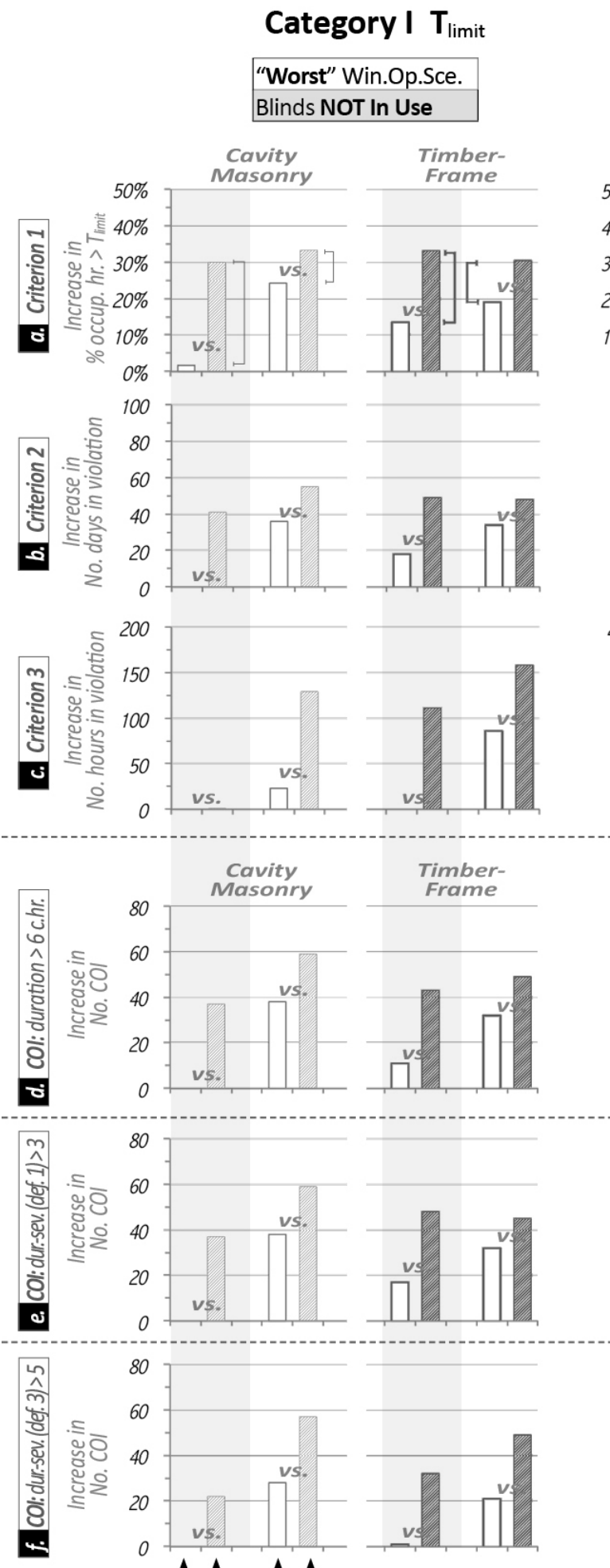

Category III $\mathbf{T}_{\text {limit }}$

"Worst" Win.Op.Sce. Blinds NOT In Use
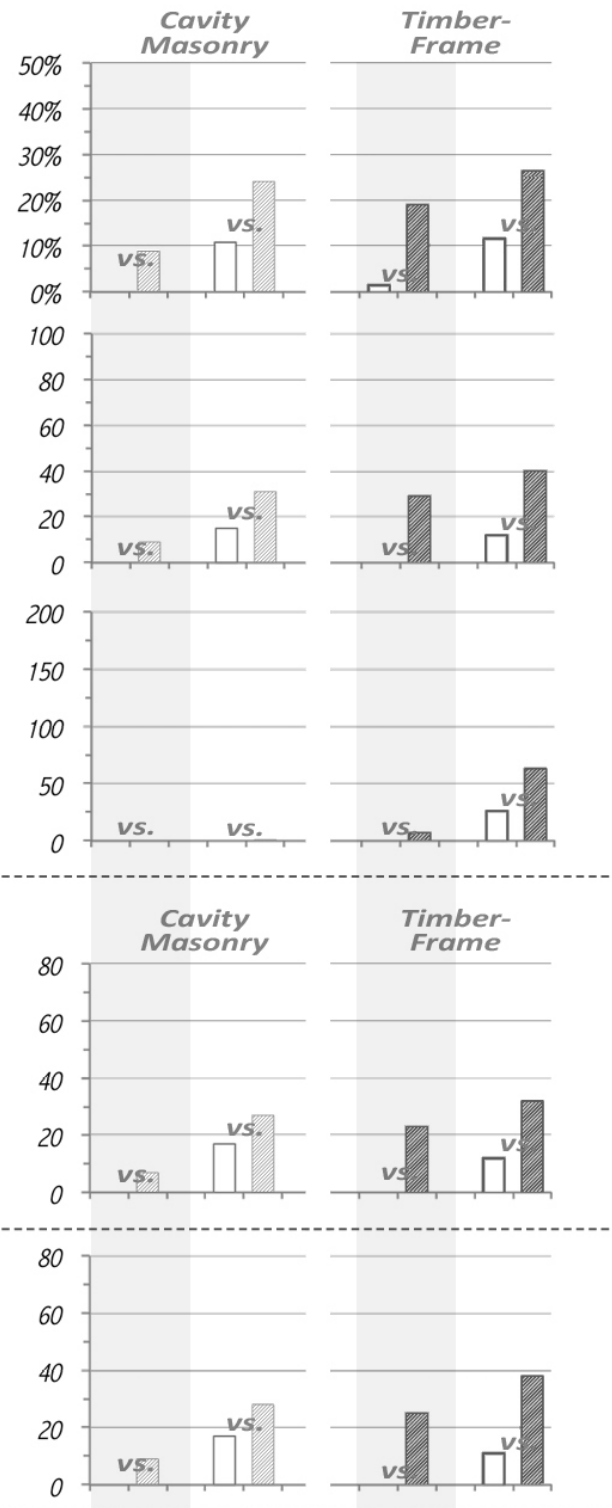

80

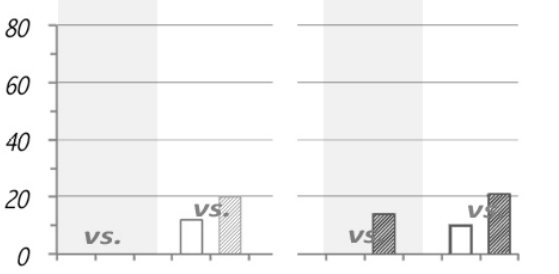

Key:

increase due to climate change from 2030 to 2080

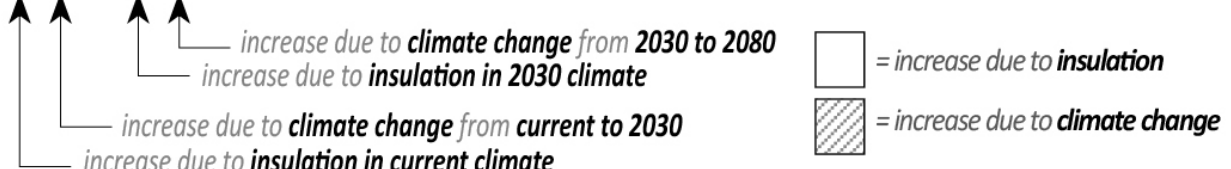

Figure 7: Absolute difference between the uninsulated and insulated constructions versus the absolute difference between climate scenarios. 
On the whole, results from the overheating assessment using the COI approach supported the results from using the TM52 criteria. But the COI assessments explicitly illustrated that the hours that exceeded the thresholds occurred in clusters, meaning there would be several instances where the entire night would be overheated. Furthermore, as only the occupied night-time (a nine-hour stretch) was considered, there may have been much longer-lasting COls that were overlooked because any COIs longer than nine hours would have been 'cut short'. Arguably, much longer COIs may be of little interest if the occupants are not present to experience it. Nevertheless, for the fragile populations (elderly, infants, ill or disabled) who are the most vulnerable to heat stress and are most likely to stay in the same room for prolonged periods of time, it becomes especially important to examine the full extent of the heat exposure duration they may experience.

Overall, cavity masonry constructions generally incurred more COls lasting longer than six consecutive hours than did timber frame. Furthermore, within each construction weight, it was the insulated variant that also incurred more such COls than its un-retrofitted counterpart. Together these trends make an interesting comparison between refurbished cavity masonry construction and uninsulated timber frame. The results suggest that it is the insulated cavity masonry construction that tends to have the most COls such that it consistently fared worse than the uninsulated timberframe construction and even the insulated timber-frame construction under the 2080 climate scenarios (columns 6-7 in Figure 6).

In terms of the effect of fabric interactions, it was observed that either the window or the blind operation alone was very effective in reducing the extent of TM52 criteria violations and the number of COls. These results indicate that, unsurprisingly, ventilation is of the utmost importance when insulation is implemented, especially for heavyweight constructions. Otherwise the benefits of having thermal mass can easily backfire to become a disadvantage. Nevertheless, ventilation is largely a result of occupant behaviour and therefore a dynamic, albeit indirect, design variable. While its implementation cannot be predetermined in the same way as deciding on the window size or construction material, it should be considered during the design process so that window operation is not only possible but also expedient for occupants. More importantly, occupants should be explicitly informed on the amount of ventilation their residence would require. As the results in this case study demonstrate, although ventilation throughout the night is ultimately the ideal strategy, a mere four-hour evening ventilation can still appreciatively improve the overheating condition.

Finally, it is evident that the additional information provided by COls comes at a cost of ease in interpretability. In the assessment based on TM52 criteria, differences among the constructions can be simply discerned. That is, the construction with the highest percentage of hours over the threshold (criterion 1), the most number of the days violating criterion 2 and the most number of hours violating criterion 3 is clearly the 'worst.' Such straightforward interpretations are the results of aggregation, which - as demonstrated in Part A above - cannot inform us on how a particular overheated situation unfolds, which is how the occupants would have experienced it. Overheating, whether understood with respect to discomfort (low level heat stress) or to health (higher level heat stress), is not an instantaneous phenomenon or an 'averaged' state. Rather, it is a process that develops over time. As such, its effect should be evaluated based on more than the sum of its parts. But there is a trade-off; it is difficult simultaneously to capture the complexity of an overheated situation and present that complexity in a simplified manner.

This interpretability issue, however, can be ameliorated once more is learned about the mechanism of how prolonged heat exposure affects health. Specifically, that knowledge will help establish benchmarks for the $\mathrm{COI}$ metrics introduced in this paper. For instance, meaningful health impact interpretations - such as 'heat exhaustion likely' or 'heat cramps possible for vulnerable individuals' - can be associated with COI:duration- severity value greater than a certain threshold (e.g. 5 for definition 3, or 3 for definition 1, as shown in Figures 5 and 6). This 'plain-language' interpretation will facilitate integration of $\mathrm{COI}$ metrics into existing assessment procedures such as TM52 and may be used to anticipate particularly vulnerable heat stress locations when coupled with 
reliable building stock information and performance modelling. Finally, even for other industry standards such as ASHRAE Standard 55 as well as for monitored data in field studies, it is possible to apply the $\mathrm{COI}$ approach because it utilizes the exact same time-series data required for existing overheating and thermal comfort assessment methodologies.

\section{Limitations}

In demonstrating the $\mathrm{COI}$ approach for overheating assessment to account for exposure duration, a very specific example of simulation case study was used. Because only one room (a south-facing bedroom under the roof) in one type of dwelling (mid-terraced) with a narrow set of construction variations and fabric interactions was examined, the results presented above can only be interpreted in those particular setups. Key parameters that undoubtedly would differ in real life (but nonetheless are reasonable assumptions and have been used elsewhere in the existing literature, e.g. Mavrogianni et al., 2012; and Porritt, Cropper, Shao, \& Goodier, 2012) are the window-operating scenarios and the extent of natural ventilation that can be achieved, as well as occupancy schedule. Although logic would dictate that occupants open windows to the maximum capacity whenever it is environmentally advantageous to do so (i.e. outdoor temperature below indoor temperature, and indoor temperature is above the comfort threshold), practical issues such as security, noise, air pollution, privacy, light pollution and mobility (especially for the elderly and disabled) inevitably would influence occupants' behaviour and whether they would be inclined to leave the windows open while not at home or sleeping. In addition, the level of clothing, bedding and activity are also contextual factors that could affect what the occupants deem as comfortable from moment to moment and prompt them to open/close windows; not to mention occupants' potentially fallible perception in determining whether the outside air is indeed cooler than the inside. These factors, as well as the use of mechanical fans and the effect of cross-ventilation via open internal doors, will need to be further explored and examined carefully in future research, where microclimatic issues such as urban heat island effects will be incorporated by using the CIBSE TM49 DSY weather files for London. An important step in future works would also entail comparisons against monitored studies, where the effect of actual occupancy schedule and behaviour would become more evident. It should be noted that the night-time-only focus discussed in this paper may not be the most representative of the hours occupied by the vulnerable population (for whom the Category I thresholds were used) as they may be less mobile and tend to spend more time in the bedroom.

\section{CONCLUSIONS}

This paper has presented an innovative way of assessing indoor overheating that departs from the status quo and highlights aspects of the overheated state that cannot be diagnosed using existing assessment methods. The proposed new approach - COls - unpacks the state of overheating to reveal stretches of time where heat stress persists continuously. These intervals may be particularly debilitating and therefore warrant special attention, yet they are often 'buried' within the existing preferred approach of aggregated assessments, which focus on the non-heating season as a whole and is based on binary judgements. The fundamental problem with an aggregation- based evaluation is that it does not acknowledge the temporal influence of heat stress nor does it differentiate instances where the exceedances of acceptability occur together or intermittently. Even without the support from health sciences, logic and common experience would dictate that being exposed to excess warmth for a short moment or two is a completely different experience than having to endure a significant amount of time in the same environment.

In the energy retrofit case study demonstration, it is apparent that timber-frame construction generally performed worse than cavity masonry within the specific setup modelled. But without natural ventilation or solar protection, the overheating exacerbating effect of insulation trumps the potential ameliorative capacity of thermal mass. In this particular case of a south-facing 
bedroom under the roof of a mid-terraced dwelling occupied only at night-time, increase in overheating due to insulation is generally lower than the increase due to climate change, but the warmer the climate the more exacerbating insulation becomes. Significant improvements could be achieved via blind and window operations, but neither lowering the blinds nor four hours of evening ventilation alone or combined would be enough to eliminate overheating altogether. That can only be achieved with constant natural ventilation, which may not be practical or realistic due to security, noise and privacy concerns. As only the occupied hours at night were examined in this demonstration case study, it is likely that the extent of overheating - either by TM52 standard or the $\mathrm{COI}$ approach - would be much worse during the day if there is no provision of sufficient ventilation or solar protection.

Finally, overall the $\mathrm{COI}$ approach supported the trends observed from the existing approach using TM52 criteria. But by acknowledging the temporal dimension of heat stress, the COI approach imparts insights into how an uncomfortably hot indoor condition unfolds overtime, and constructs a more representative picture of the thermal situation in the way it would have been experienced by the occupants in real time. Although this consideration of exposure duration can yet provide direct interpretations to specific health impacts, the field of health sciences is underway to learn more about the biological effects of prolonged heat exposure.

While it is important to recognize that the results from the case study demonstration are not generalizable due to the narrow scope of the modelling setup, the proposed COI assessment approach designed to account for overheating exposure duration nevertheless has broader applications. It must be emphasized that because the COI approach utilizes the exact same timeseries data required for existing overheating assessment protocols, this proposed new approach does not replace TM52 or similar aggregated methods but rather serves as a detailed elaboration of these established standards. Ultimately, the better building professionals understand the indoor thermal environment in terms of exposure duration, the better building research will be able to link up with the upcoming findings from health research toward an overall deeper comprehension of how heat affects health and how best to reduce anticipated heat-related health impacts in the face of climate change.

\section{Acknowledgements}

W. V. Lee is currently affiliated with Columbia University, but the research reported in this paper was conducted while Lee was affiliated with The Martin Centre for Architectural and Urban Studies, Department of Architecture, University of Cambridge, UK.

\section{Funding}

The authors gratefully acknowledge the support of the Gates Cambridge Trust.

\section{REFERENCES}

Anderson, G. B., \& Bell, M. L. (2011). Heat waves in the United States: Mortality risk during heat waves and effect modification by heat wave characteristics in 43 US communities. Environmental Health Perspectives, 119(2), 210-218. doi:10.1289/ehp.1002313

Anderson, M., Carmichael, C., Murray, V., Dengel, A., \& Swainson, M. (2013). Defining indoor heat thresholds for health in the UK. Perspectives in Public Health, 133(3), 158-164. doi:10.1177/1757913912453411

American Society of Heating Refrigerating and Air- Conditioning Engineers (ASHRAE). (2009). ASHRAE handbook: Fundamentals (SI edition). Atlanta, GA: ASHRAE.

Armstrong, B. G., Chalabi, Z., Fenn, B., \& Hajat, S. (2011). Association of mortality with high temperatures in a temperate climate: England and Wales. Journal of Epidemiology and Community Health, 65(4), 340-345. Retrieved from 
http://jech.bmj.com/content/early/2010/05/03/jech.2009.093161.short doi:10.1136/jech.2009.093161

Barnett, A. G., Hajat, S., Gasparrini, A., \& Rocklov, J. (2012). Cold and heat waves in the United States. Environmental Research, 112, 218-224. doi:10.1016/j.envres.2011.12.010

BRE. (2010). The government's standard assessment procedure for energy rating of dwellings, SAP 2009 version 9.90, October 2009. Garston: BRE.

British Standard Institute (BSI). (1994). ISO 7243: 1989: Hot environments - Estimation of the heat stress on working man, based on the WBGT-index (wet-bulb globe temperature). London: BSI.

British Standard Institute (BSI). (2005). ISO 7933:2004 Ergonomics of the thermal environment Analytical determination and interpretation of heat stress using calculation of the predicted heat strain. London: BSI.

British Standard Institute (BSI). (2007). BSEN 15251: Indoor environmental input parameters for design and assessment of energy performance of buildings addressing indoor air quality, thermal environment, lighting and acoustics. London: BSI.

Carlucci, S., \& Pagliano, L. (2012). A review of indices for the long-term evaluation of the general thermal comfort conditions in buildings. Energy and Buildings, 53, 194-205. doi:10.1016/j.enbuild.2012.06.015

Chartered Institution of Building Service Engineers (CIBSE). (2007). Guide A: Environmental design. London: CIBSE.

Chartered Institution of Building Service Engineers (CIBSE). (2013). Technical memorandum TM52: The limits of thermal comfort: Avoiding overheating in European buildings. London: CIBSE.

Chartered Institution of Building Service Engineers (CIBSE). (2015). Guide A: Environmental design. London: CIBSE.

de Dear, R. J., \& Brager, G. S. (2002). Thermal comfort in naturally ventilated buildings: Revisions to ASHRAE Standard 55. Energy and Buildings, 34(6), 549-561. doi:10.1016/ S03787788(02)00005-1

Department of Communities and Local Government (DCLG). (2010). English housing survey, 2010: Housing stock data, 2nd Edition [Data set]. Retrieved September 28, 2012, from http://dx.doi.org/10.5255/UKDA-SN-7039-2

Department of Communities and Local Government (DCLG). (2013). English housing survey: HOMES annual report on England's housing stock, 2011. London: DCLG.

Department of Energy and Climate Change (DECC). (2014). 2013 UK greenhouse gas emissions, provisional figures and 2012 UK greenhouse gas emissions, final figures by fuel type and enduser: Statistical release. Retrieved from https://www.

gov.uk/government/uploads/system/uploads/attachment_ data/file/295968/20140327_2013_UK_Greenhouse_Gas_Emissions_Provisional_Figures.pdf

Diaz, J., Jordian, A., Garcia, R., Lopez, C., Alberdi, J. C., Hernandez, E., \& Otero, A. (2002). Heat waves in Madrid 1986-1997: Effects on the health of the elderly. International Archives of Occupational and Environmental Health, 75(3), 163-170. doi:10.1007/s00420-001-0290-4

D'Ippoliti, D., Michelozzi, P., Marino, C., de'Donato, F., Menne, B., Katsouyanni, K., Perucci, C. A. (2010). The impact of heat waves on mortality in 9 European cities: Results from the EuroHEAT project. Environmental Health, 9, 190. Retrieved from http://ehjournal.biomedcentral.com/ articles/10.1186/1476-069X-9-37

Eames, M., Kershaw, T., \& Coley, D. (2011). On the creation of future probabilistic design weather years from UKCP09. Building Services Engineering Research and Technology, 32 (2), 127142. doi:10.1177/0143624410379934

Epstein, Y., \& Moran, D. S. (2006). Thermal comfort and the heat stress indices. Industrial Health, 44, 388-398. doi:10. 2486/indhealth.44.388 
Fouillet, A., Rey, G., Laurent, F., Pavillon, G., Bellec, S., Guihenneuc-Jouyaux, C., Hemon, D. (2006). Excess mortality related to the August 2003 heat wave in France. International Archives of Occupational and Environmental Health, 80(1), 16-24. doi:10.1007/s00420-006-0089-4

Gosling, S. N., McGregor, G. R., \& Lowe, J. A. (2009). Climate change and heat-related mortality in six cities part 2: Climate model evaluation and projected impacts from changes in the mean and variability of temperature with climate change. International Journal of Biometeorology, 53(1), 31-51. doi:10.1007/s00484-008-0189-9

Greater London Authority. (2008). Your home in a changing climate: Retrofitting Existing Homes for Climate Change Impacts. Retrieved from http://media.climateuk.net/sites/ default/files/Your-home-in-a-changing-climate.pdf

Gul, M. S., \& Menzies, G. F. (2012). Designing domestic buildings for future summers: Attitudes and opinions of building professionals. Energy Policy, 45, 752-761. doi:10.1016/j. enpol.2012.03.046

Gupta, R., \& Gregg, M. (2012). Using UK climate change projections to adapt existing English homes for a warming climate. Building and Environment, 55(7), 20-42. doi:10.1016/ j.buildenv.2012.01.014

Hacker, J. N. (2008). Modelling passive and active cooling strategies for housing under present and projected future climate-A case study of London. Proceedings from Proceedings of Conference: Air Conditioning and the Low Carbon Cooling Challenge, Cumberland Lodge, Windsor, UK.

Hajat, S., \& Kosatky T. (2010). Heat-related mortality: A review and exploration of heterogeneity. Journal of Epidemiology and Community Health, 64, 753-760. doi:10. 1136/jech.2009.087999

Hajat, S., Kovats, R. S., Atkinson, R. W., \& Haines, A. (2002). Impact of hot temperatures on death in London: A time series approach. Journal of Epidemiology and Community Health, 56(5), 367372. doi:10.1136/jech.56.5.367

Hajat, S., Kovats, R. S., \& Lachowycz, K. (2007). Heat-related and cold-related deaths in England and Wales: Who is at risk? Occupational and Environmental Medicine, 64(2), 93-100. doi:10.1136/oem.2006.029017

Hajat, S., Vardoulakis, S., Heaviside, C., \& Eggen, B. (2014). Climate change effects on human health: Projections of temperature-related mortality for the UK during the 2020s, 2050s and 2080s. Journal of Epidemiology and Community Health, 68(7), 641-648. doi:10.1136/jech-2013202449

Integrated Environmental Solutions Virtual Environment (IES-VE). (Version 6.4) [Computer software]. Glasgow: Integrated Environmental Solutions Limited.

IPCC. (2012). Managing the risks of extreme events and disasters to advance climate change adaptation: A special report ofWorking Groups I and II of the Intergovernmental Panel on Climate Change. Cambridge: Cambridge University Press, 2012.

Johnson, H., Kovats, R. S., McGregor, G., Stedman, J., Gibbs, M., \& Walton, H. (2005). The impact of the 2003 heat wave on daily mortality in England and Wales and the use of rapid weekly mortality estimates. Euro Surveillance, 10(7), 168-171.

Kalkstein, L. S., \& Davis, R. E. (1989). Weather and human mortality: An evaluation of demographic and interregional responses in the United States. Annals of the Association of American Geographers, 79(1), 44-64. doi:10.1111/j. 1467-8306.1989.tb00249.x

Kershaw, T., Eames, M., \& Coley, D. (2011). Assessing the risk of climate change for buildings: A comparison between multi-year and probabilistic reference year simulations. Building and Environment, 46, 1303-1308.

Kinney, P., O'Neill, M., Bell, M., \& Schwartz, J. (2008). Approaches for estimating effects of climate change on heat-related deaths: Challenges and opportunities. Environmental Science and Policy, 11(1), 87-96. doi:10. 1016/j.envsci.2007.08.001 
Levermore, G. J., \& Parkinson, J. B. (2006). Analyses and algorithms for new test reference years and design summer years for the UK. Building Service Engineering Research and Technology, 27(4), 311-325. doi:10.1177/0143624406071037

Lin, Y. K., Ho, T. J., \& Wang, Y. C. (2011). Mortality risk associated with temperature and prolonged temperature extremes in elderly populations in Taiwan. Environmental Research, 111(8), 1156-1163. doi:10.1016/j.envres.2011.06.008

Maller, C. J., \& Strengers, Y. (2011). Housing, heat stress and health in a changing climate: Promoting the adaptive capacity of vulnerable households, a suggested way forward. Health Promotion International, 26(4), 492-498. doi:10. 1093/heapro/dar003

Marmor, M. (1978). Heat wave mortality in nursing homes. Environmental Research, 17(1), 102-115. doi:10.1016/0013-9351(78)90065-8

Mavrogianni, A., Oikonomou, E., Das, P., Davies, M., Raslan, R., Jones, B.,...Shrubsole, C. (2013). The unintended consequences of energy efficient retrofit on indoor overheating and air pollution risk in a typical Edwardian mid-terraced house. Proceedings from FutureBuild 2013, Bath, UK.

Mavrogianni, A., Wilkinson, P., Davies, M., Biddulph, P., \& Oikonomou, E. (2012). Building characteristics as determinants of propensity to high indoor summer temperatures in London dwellings. Building and Environment, 55, 117-130. doi:10.1016/j.buildenv.2011.12.003

Met Office UK. (2015). Heat-health watch. Retrieved from http://www.metoffice.gov.uk/public/weather/heat-health/\#? tab=heatHealth

Montero, J. C., Miron, I. J., Criado, J. J., Linares, C., \& Diaz, J. (2010). Comparison between two methods of defining heat waves: A retrospective study in Castile-La Mancha (Spain). Science of The Total Environment, 408(7), 1544-1550. doi:10. 1016/j.scitotenv.2010.01.013:10.1016/j.scitotenv.2010.01.013

Nakai, S., Itoh, T., \& Morimoto, T. (1999). Deaths from heatstroke in Japan: 1968-1994. International Journal of Biometeorology, 43(3), 124-127. doi:10.1016/S1572-347X (05)80013-8

The National Archives. (2008). Climate change act 2008, chapter 27. Retrieved from http://www.legislation.gov.uk/ukpga/ 2008/27/contents

National Oceanic and Atmospheric Administration (NOAA). 2011. Heat: A major killer. Retrieved May 10, 2011, from http://www.nws.noaa.gov/om/heat/index.shtml

Nicol, J. F., Hacker, J., Spires, B., \& Davies, H. (2009). Suggestion for new approach to overheating diagnostics. Building Research \& Information, 37(4), 348-357. doi:10. 1080/09613210902904981:10.1080/09613210902904981

Oikonomou, E., Davies, M., Mavrogianni, A., Biddulph, P., Wilkinson, P., \& Kolokotroni, M. (2012). Modelling the relative importance of the urban heat island and the thermal quality of dwellings for overheating in London. Building and Environment, 57, 223-238. doi:10.1016/j.buildenv.2012.04.002

Parsons, K. (2003). Human thermal environments: The effects of hot, moderate, and cold environments on human health, comfort and performance ( $2 \mathrm{nd}$ ed.). London: Taylor \& Francis.

Porritt, S. M., Cropper, P. C., Shao, L., \& Goodier, C. I. (2012). Ranking of interventions to reduce dwelling overheating during heat waves. Energy and Buildings, 55, 16-27. doi:10.1016/j.enbuild.2012.01.043

Rijal, H. B., Tuohy, P., Humphreys, M. A., Nicol, J. F., \& Samuel, A. (2012). Considering the impact of situationspecific motivations and constraints in the design of naturally ventilated and hybrid buildings. Architectural Science Review, 55(1), 35-48. doi:10.1080/00038628.2011.641734

Robine, J. M., Cheung, S. L., Le Roy, S., Van Oyen, H., Griffiths, C., Michel, J. P., \& Herrmann, F. R. (2008). Death toll exceeded 70,000 in Europe during the summer of 2003. Comptes Rendus Biologies, 331(2), 171-178. doi:10.1016/j.crvi.2007.12.001 
Rocklov, J., Barnett, A. G., \& Woodward, A. (2012). On the estimation of heat-intensity and heatduration effects in time series models of temperature-related mortality in Stockholm, Sweden. Environmental Health, 11-23. doi:10. 1186/1476-069X-11-23

Rocklov, J., Ebi, K., \& Forsberg, B. (2011). Mortality related to temperature and persistent extreme temperatures: A study of cause-specific and age-stratified mortality. Occupational and Environmental Medicine, 68(7), 531-536. doi:10.1136/ oem.2010.058818

Semenza, J. C., Rubin, C. H., Falter, K. H., Selanikio, J. D., Flanders, W. D., Howe, H. L., \& Wilhelm, J. L. (1996). Heat-related deaths during the July 1995 heat wave in Chicago. The New England Journal of Medicine, 335(2), 84-90. doi:10.1056/NEJM199607113350203

Sharpe, T., \& Shearer, D. (2013). Scenario testing of the energy and environmental performance of the 'Glasgow House'. Proceedings from PLEA2013-29th Conference, Sustainable Architecture for a Renewable Future, Munich, Germany.

Shrubsole, C., Macmillan, A., Davies, M., \& May, N. (2014). 100 unintended consequences of policies to improve the energy efficiency of the UK housing stock. Indoor and Built Environment, 23(3), 340-352. doi:10.1177/ 1420326X14524586

Smoyer, K. E. (1998). A comparative analysis of heat waves and associated mortality in St. Louis, Missouri-1980 and 1995. International Journal of Biometeorology, 42(1), 44- 50. doi:10.1007/s004840050082

Smoyer-Tomic, K. E., Kuhn, R., \& Hudson, A. (2003). Heat wave hazards: An overview of heat wave impacts in Canada. Natural Hazards, 28:463-485.

Spires, B. (2011). How to assess overheating: Key design issues - The new TM on overheating, the new comfort calculator. Paper presented at the Summertime Overheating In Buildings and Urban Environments Conference, 21 July 2011, London, UK.

Tan, J., Zheng, Y., Song, G., Kalkstein, L. S., Kalkstein, A. J., \& Tang, X. (2007). Heat wave impacts on mortality in Shanghai, 1998 and 2003. International Journal of Biometeorology, 51(3), 193200. doi:10.1007/s00484-006-0058-3

Tan, J., Zheng, Y., Tang, X., Guo, C., Li, L., Song, G., Chen, H. (2010). The urban heat island and its impact on heat waves and human health in Shanghai. International Journal of Biometeorology, 54(1), 75-84. doi:10.1007/ s00484-009-0256-x:10.1007/s00484-009-0256-x

Weisskopf, M. G., Anderson, H. A., Foldy, S., Hanrahan, L. P., Blair, K., Török, T. J., \& Rumm, P. D. (2002). Heat wave morbidity and mortality, Milwaukee, Wis, 1999 vs 1995: An improved response? American Journal of Public Health, 92(5), 830-833. doi:10.2105/AJPH.92.5.830

Williams, S., Nitschke,M., Sullivan, T., Tucker, G. R.,Weinstein, P., Pisaniello, D. L.,...Bi, P. (2012). Heat and health in Adelaide, South Australia: Assessment of heat thresholds and temperature relationships. Science of The Total Environment, 414, 126-133.

doi:10.1016/j.scitotenv.2011.11.038

WMO. (2011). WMO statement on the status of the global climate in 2010. Retrieved from http://www.wmo.int/pages/prog/wcp/wcdmp/documents/1074_en.pdf

Yun, G. Y., \& Steemers, K. (2008). Time-dependent occupant behaviour models of window control in summer. Building and Environment, 43, 1471-1482. doi:10.1016/j.buildenv. 2007.08.001

Zero Carbon Hub. (2015). Assessing overheating risk - Evidence review. Retrieved from http://www. zerocarbonhub.org/sites/default/files/resources/reports/ ZCH-OverheatingEvidenceReviewMethodologies.pdf 